Document downloaded from:

http://hdl.handle.net/10251/67092

This paper must be cited as:

Luján, JM.; Bermúdez, V.; Piqueras, P.; Garcia Afonso, O. (2015). Experimental assessment of pre-turbo aftertreatment configurations in a single stage turbocharged diesel engine. Part 1: Steady-state operation. Energy. 80:599-613. doi:10.1016/j.energy.2014.05.048.

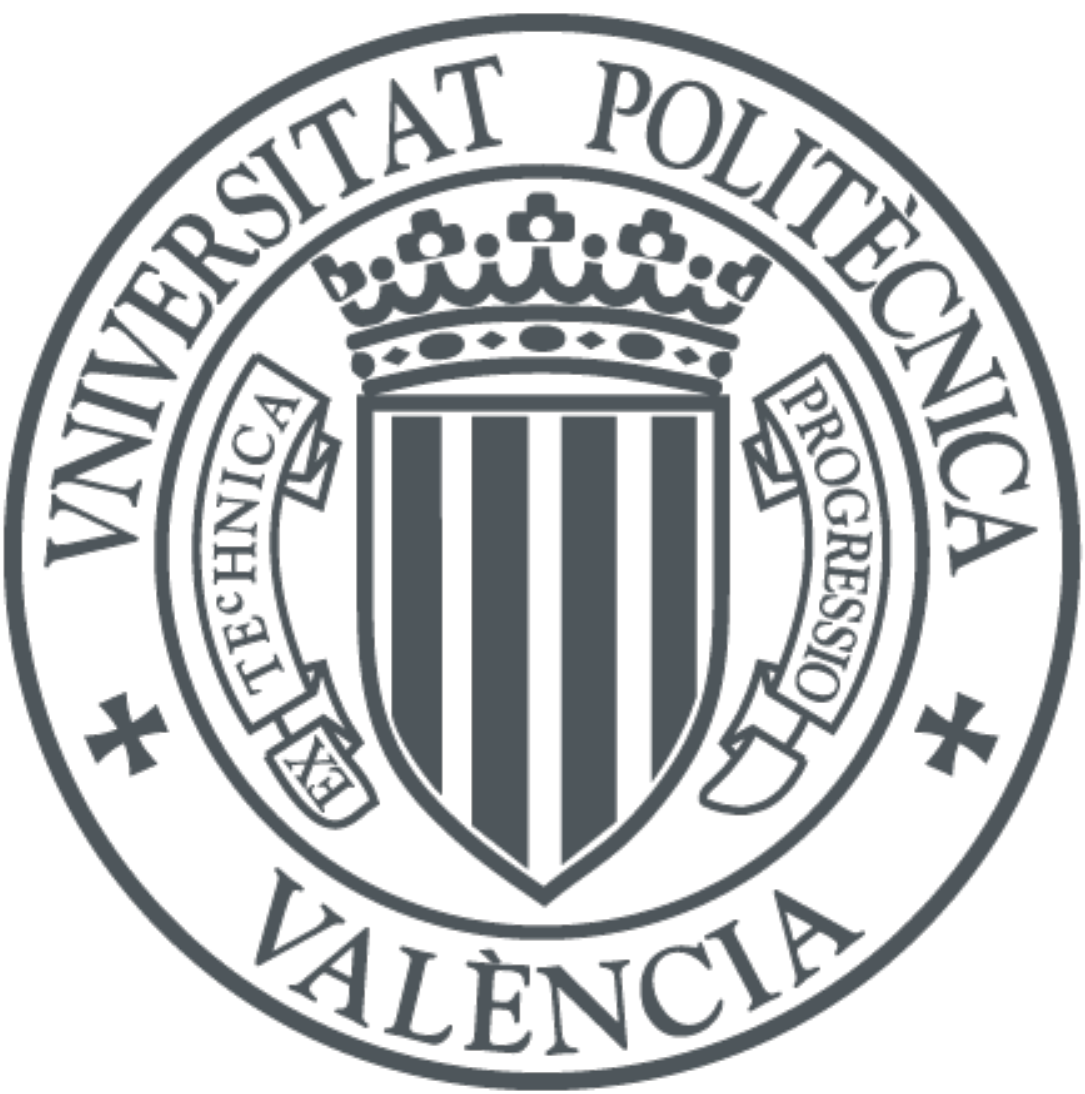

The final publication is available at

http://dx.doi.org/10.1016/j.energy.2014.05.048

Copyright Elsevier

Additional Information 


\title{
Experimental assessment of pre-turbo aftertreatment configurations in a single stage turbocharged Diesel engine. Part 1: Steady-state operation
}

\author{
José Manuel Luján, Vicente Bermúdez, Pedro Piqueras *, Óscar García-Afonso \\ Universitat Politècnica de València, CMT-Motores Térmicos, Camino de Vera s/n, 46022 Valencia, Spain.
}

\begin{abstract}
Diesel oxidation catalysts and diesel particulate filters are standard aftertreatment systems in Diesel engines which are traditionally placed downstream of the turbine. However, pre-turbo aftertreatment configurations are being approached as a way to improve the aftertreatment performance in terms of light-off and passive regeneration. This exhaust line architecture can also benefit fuel economy. The objective of this work is to analyse experimentally how the pre-turbo aftertreatment placement impacts on the performance of a single stage turbocharged Diesel engine.

The work has been divided into two parts focused on steady-state and transient engine operation separately. The first part comprises the analysis of the experimental results corresponding to steady-state operating conditions. The range of operation covers different engine loads and speeds. The engine response with pre-turbo aftertreatment placement is mainly affected by the change in the pumping work caused by the aftertreatment pressure drop reduction and its new location, which avoids the multiplicative effect of the turbine expansion ratio when setting the engine back-pressure. These effects become more significant as the engine load increases benefiting fuel consumption from low to high loads. Concerning aftertreatment performance, the results evidence noticeable benefits in DPF passive regeneration and $\mathrm{CO} / \mathrm{HC}$ emissions reduction at low engine load.
\end{abstract}

Keywords: Diesel engine, aftertreatment, pre-turbo aftertreatment configuration, steady-state operation, fuel consumption, emissions

\section{Introduction}

Direct injection Diesel engines present the best approach to $\mathrm{CO}_{2}$ emission reduction among internal combustion engines, mainly due to the strong improvements undergone in last decades in terms of fuel consumption and pollutant emissions reduction [1]. Examples of this process are the continuous advances in boosting understanding [2] and architectures development including supercharger [3] and two-stage turbocharging [4] solutions, combustion process analysis [5] or the use of fuel blends [6]. Particularly, many research efforts have been focused on the reduction of pollutant emissions. Up to the present century, the only use of diesel oxidation catalysts (DOC), as a solely

${ }^{*}$ P. Piqueras. CMT-Motores Térmicos, Universitat Politècnica de València, Camino de Vera s/n, 46022 Valencia, Spain. Phone: +34 963877650 Fax: +34 963877659 e-mail: pedpicab@ mot.upv.es 
aftertreatment system, in junction with improvements in the engine technology, such as the exhaust gas recirculation (EGR) [7] and the injection process, were enough to fulfil the emission standards. However, current and future regulations are forcing manufacturers to include additional aftertreatment systems such as diesel particulate filter (DPF) and lean NOx traps (LNT) or selective catalyst reduction (SCR) technologies.

The characteristic excess of air in Diesel engines results in low exhaust gas temperature compared to that of gasoline engines. This fact conditions the performance of the DOC and deNOx system because of the light-off time, and the passive soot oxidation in the DPF. An attractive solution to overcome these issues arises from placing the aftertreatment upstream of the turbine, looking for higher thermal level [8] with additional improvements in terms of clean high-pressure EGR [9].

Most of the studies regarding pre-turbo aftertreatment configurations have been only focused on the pre-turbo placement of the DOC, locating it in different regions in the exhaust manifold [10]: exhaust ports or the interface between the exhaust manifold and the turbine. The higher temperature in these regions is favourable in terms of reducing $\mathrm{HC}$ and $\mathrm{CO}$ emissions during the engine warm-up [12]. Moreover it is obtained higher mass transfer between the exhaust gas and the channel walls due to the flow conditions upstream of the turbine, which contributes to reach high conversion efficiency even with small catalyst volume [11] what leads to engine efficiency increase [12].

Despite the fact that the first developments of DPFs in pre-turbo configuration were performed during the 80s [13], this solution was dismissed because of the low structural properties of the monoliths leading to the cordierite failure and hence damaging the turbine blades. However, the new DPF generations, which are characterised by important improvements in terms of reliability and durability [14], in junction with the possibility to make use of metallic DOCs placed between the DPF and the turbine [15] are boosting again the interest by this aftertreatment placement both in road [16] and non-road applications [17].

Previous modelling studies of the authors have identified the pre-turbo aftertreatment placement as a solution to reduce the pressure drop across the DPF due to the flow conditions upstream of the turbine [18]. It is a first reason contributing to reduce the engine pumping work but the main advantage comes from the new placement of such an aftertreatment pressure drop. When it is located upstream of the turbine, the engine back-pressure is set by the addition of the aftertreatment pressure drop and the turbine expansion ratio times the ambient pressure. It contrasts with the traditional post-turbo aftertreatment placement, which imposes a higher back-pressure given by the turbine expansion ratio times the sum of ambient pressure and aftertreatment pressure drop [16]. As the DPF becomes loaded, this effect turns out very positive since the global engine performance with pre-turbo configuration is much less sensitive to soot loading, especially in aspects like bsfc increase and control on EGR valve and VGT position [19].

As regards the turbocharging, the aftertreatment systems produce the lamination of the pulsating flow resulting in constant pressure turbocharging [20]. It means the lack of energy associated to the pulses but also may contribute to improve the turbine design and efficiency [20]. Other benefits derived from the pre-turbo DOC and DPF placement are related to: the potential for monolith volume reduction [21]; possibility to obtain clean high-pressure EGR; improvement of the gas-urea mixing without the need of swirl generators due to swirl induced at the turbine outlet able to 
be used at the inlet of the SCR; the possibility for EGR pre-cooling through an air gap surrounding the aftertreatment [9]; and flexibility for exhaust manifold tuning [15].

Most of these conclusions about pre-turbo aftertreatment placement in modern engines are based on modelling approach. The aim of this work, which is divided into two parts, is to overcome the lack of experimental information by means of the analysis of the response of a single stage turbocharged Diesel engine for passenger car application. The study comprises the engine testing both with post-and pre-turbo aftertreatment placement. This first part of the study is devoted to the analysis under steady-state operating conditions whereas the second part focuses on transient operating conditions. In this paper the response of the engine in terms of fuel consumption and emissions is analysed under steady-state operating conditions at low engine load points selected from the New European Driving Cycle (NEDC) and at medium to high load operating conditions covering all the engine speed range.

\section{Experimental setup}

The study has been performed in a single stage turbocharged Diesel engine for passenger car application. The engine is fulfilling Euro 4 emission standards. Table 1 summarises its main characteristics.

The engine has been installed in a test cell equipped with a $250 \mathrm{~kW}$ asynchronous dynamometer SHENCK Dynas Li250 able to control engine speed and torque under steady-state and transient operating conditions. In order to provide modifications in the engine operating parameters, an open code engine control unit (ECU) allows modifying the engine calibration through ETAS INCA software. ECU calibration has not been modified during the study, with the only exception of the VGT position to control the boost pressure in the EGR operating region. The engine cooling system and the charge air cooler are connected to external water circuits for accurate temperature control. Additionally, the engine has been instrumented with sensors to measure main magnitudes defining the engine and aftertreatment performance: temperature, mean and instantaneous pressure along the air path, air and fuel mass flow, engine speed, engine torque and turbocharger speed. Table 2 summarises the main characteristics of the instrumentation.

Besides temperature and mean pressure measurement along the air path, instantaneous pressure sensors have been located at the inlet of the aftertreatment systems and turbine in order to assess the effect of the pre-turbo aftertreatment placement on pulsating flow. The data acquisition system used was a Yokogawa DL716 oscilloscope synchronised with an optical angular encoder with a resolution of 0.2 CAD.

The air mass flow has been measured with a hot-wire anemometer whose measurement range is 0 to $720 \mathrm{~kg} / \mathrm{h}$. Two systems have been applied to measure the fuel consumption. A fuel gravimetric balance has been used under steady-state operation because of its high accuracy. However, this kind of system is characterized by slow dynamics. Therefore the volumetric fuel mass flow provided by the ECU, which is a signal of higher frequency, has been also considered. It is sensitive to any instantaneous change in the rate of fuel injected. Therefore, its use becomes appropriate during transient operation. Nevertheless, since it is not a direct measurement but a calculation, it was 
calibrated under steady-state operation with the measurements performed by the gravimetric balance according to the methodology proposed by Serrano et al. [22].

A Horiba Mexa 7100 DEGR has been used to measure the exhaust gas emissions at the tailpipe downstream of the aftertreatment system and the intake $\mathrm{CO}_{2}$ concentration. In the same way, an AVL 439 opacimeter has been installed to measure the smoke opacity. Additionally a TSI EEPS (Engine Exhaust Particle Sizer) has been employed to measure the total particle concentration. The TSI EEPS was installed coupled to a valve system allowing the alternative measurement upstream and downstream of the DPF in order to provide a figure of the DPF filtration efficiency.

\subsection{Exhaust line architectures}

The current study has comprised the evaluation of three exhaust line architectures as a function of the aftertreatment placement. Figure 1 shows the scheme of the considered exhaust lines. Plot (a) in Figure 1 corresponds to the post-turbo aftertreatment placement. This configuration is representative of Euro 4 Diesel engines. It is composed of a close-coupled DOC and an underfloor DOC followed by a wall-flow DPF.

It is convenient to note that both underfloor DOC and DPF, whose main characteristics are summarised in Table 3, are not the original aftertreatment. They were substituted by single elements that are also used in the pre-turbo aftertreatment configurations making possible to assess the effects of the relative placement of DOC and DPF. The pre-turbo aftertreatment configurations shown in Figure 1(b) and (c) come up as a result of placing the aftertreatment system upstream of the turbine removing the close-coupled DOC. These configurations only differ in the relative position of the DOC and DPF upstream of the turbine. Plot (b) sketches the pre-turbo DOC and DPF placement and plot (c) represents the case of the placement of the DPF just downstream of the exhaust manifold followed by the DOC. There are two reasons justifying the interest for the analysis of these pre-turbo aftertreatment architectures:

- The pre-turbo DOC \& DPF configuration allows promoting the soot oxidation by $\mathrm{NO}_{2}$ generated in the DOC as usually done in the traditional post-turbo aftertreatment configuration. It allows the DPF to be benefited by a higher soot oxidation rate at low temperature. Moreover, as the DOC is placed in the region of maximum temperature the time up to DOC light-off is reduced.

- The DPF \& DOC positioning is favoured by the higher thermal level before the turbine to promote the DPF passive regeneration and provides additional interest coming out due to structural aspects. As proposed by Payri et al. [15], a metallic DOC of high cell density placed downstream of the DPF may work as filter protecting the turbine from ceramic fragments released by the DPF monolith.

\subsection{Test methodology}

With the aim of bringing the pre-turbo aftertreatment evaluation under steady-state operation as close as possible to real engine operating conditions, a wide variety of running points has been selected. A total number of 11 steadystate operating conditions have been tested. The definition of these operating conditions is given in Table 4 as a 
function of the engine speed, load and EGR rate. Furthermore it is indicated the DPF inlet temperature in post-turbo aftertreatment placement as a baseline for following discussions. Every operating condition is identified with a capital letter that will be used from now on.

Operating conditions from A to E belong to the low load range of operation and have been chosen as representative of quasi-steady-state conditions of the NEDC cycle [23]. These operating points are labeled in Figure 2. Their engine speed ranges from 1,370 rpm to 2,240 rpm and the load from 5\% to 34\%. The EGR rate decreases with engine load from $48.5 \%$ to $13 \%$. In order to complete the study, 6 points in the range of medium-high load and without EGR have been selected from 1,500 rpm to 4,000 rpm each $500 \mathrm{rpm}$ reducing the load as the engine speed increases, so that it ranges from $90 \%$ to $50 \%$ (points $\mathrm{F}$ to $\mathrm{K}$ in Table 4).

The operating conditions belonging to the NEDC were measured consecutively in three different rounds distinguished by the order:

- Round 1: E-D-C-B-A

- Round 2: D-C-B-A-E

- Round 3: B-A-C-D-E

The DPF soot loading and the substrate thermal transient process play a key role on the DPF passive regeneration. Therefore, the relative position of each operating point in every round has an impact on the soot accumulation at the end of each round, i.e. in the quantity of soot mass that is passively regenerated. The procedure to measure the steady-state operating points during every round comprised the following steps:

- The DPF was regenerated and weighed in clean conditions before every round testing. In order to perform reliable measurements, the DPF was disassembled from the engine and weighed in hot conditions just after the regeneration. Weighing in hot conditions $\left(>200{ }^{\circ} \mathrm{C}\right.$ ) avoids the effects of the hygroscopic nature of the porous medium, which affects the DPF weight due to absorbed water from the ambient air. A balance with a maximum full scale error of $\pm 1 \mathrm{~g}$ was used (Table 2 ).

- The engine warm-up was performed in the first operating point of every round.

- Each operating point was measured after a previous stabilisation of $35 \mathrm{~min}$, once the engine thermal transient had been completed at any engine element.

- The DPF was weighed according to the same methodology than in clean conditions when the test round ended up. The difference between the DPF weight at the beginning and at the end of the test provided the amount of final soot mass loading in the DPF.

The measurement of the medium-high load operating points was performed according to the same methodology but independently for each operating point since the high temperature at the inlet of the DPF promoted passive regeneration. 


\section{Results and discussion}

\subsection{Aftertreatment pressure drop}

One of the main advantages that the pre-turbo aftertreatment placement brings out is the reduction of the aftertreatment pressure drop because of the higher gas density upstream of the turbine [18]. Figure 3 compares the aftertreatment pressure drop between post-and pre-turbo placements. The standard post-turbo DOC and DPF configuration involves higher pressure drop across the aftertreatment system for all the engine operating points, regardless of the engine speed and load. Nevertheless, the differences in pressure drop are only noticeable as the engine load and speed increases owing to the higher mass flow. Differences reach up to 7,000 Pa with respect to 27,000 $\mathrm{Pa}$ of pressure drop in post-turbo placement what means $25 \%$ in pressure drop reduction.

There are two reasons explaining this response. On the one hand, the gas density is higher in the pre-turbo configuration, which becomes more relevant as the engine speed and load increase. Hence the difference in pressure drop trend between upstream and downstream of the turbine. As shown in previous modelling studies [20], considering the same aftertreatment inlet cross section and the same mass flow, the velocity decreases at the inlet of the aftertreatment in pre-turbo location. As the dynamic pressure depends linearly on the gas density and squarely on the velocity, its value is lower across the aftertreatment system in a pre-turbo placement leading the pressure drop to decrease. On the other hand, the DPF pressure drop is benefited from lower soot mass loading in pre-turbo configuration due to the better conditions for passive regeneration, as it will be corroborated in Section 3.4.

Besides the positive effect of the pre-turbo aftertreatment placement on the pressure drop magnitude there is an additional effect on the flow dynamics. Due to the pressure drop location upstream of the turbine, the inherent exhaust pulsating flow at the cylinders discharge is filtered as the exhaust gases flow across the aftertreatment systems. It is involving a change in the turbocharging feature from pulsating pressure to constant pressure turbocharging. Figure 4 represents the instantaneous VGT inlet pressure for different operating points and exhaust line configurations. Plots from (a) to (c) correspond to A, C and E operating points, whereas plots (d), (e) and (f) represent the VGT inlet pressure in the case of the medium-high load operating points G, I and J. Any of the pre-turbo aftertreatment configurations presents the same effect on the flow pulsating characteristics leading to a quasi-steady pressure without any effect of the relative DOC and DPF placement on the pulse amplitude at the VGT inlet. As a consequence, the VGT is not able to take benefit from the energy associated to pulse peaks. This is especially important at low loads, like operating point $\mathrm{C}$, in which pre-turbo pressure drop and its location is of lower importance. When the energy peaks disappear in pre-turbo aftertreatment configuration it is necessary to increase the mean expansion ratio. It is shown clearly in Figure 4 and it is performed by closing the VGT at low load operating points.

The measurement of the pre-turbo aftertreatment configuration changing the relative position between DOC and DPF allows evaluating the contribution of each element to the pulse lamination. Figure 5 shows the evolution of the pulse amplitude across the different aftertreatment elements in pre-turbo configuration for steady-state operating points E and G. Plots represent the instantaneous pressure from the inlet of the first aftertreatment element towards 
the turbine inlet. In the first measured location (plots (a) and (d) for operating points $E$ and $G$ respectively) both pre-turbo configurations present the same pulse amplitude. Mean pressure is slightly higher in pre-turbo DOC and DPF placement in the case of operating point $\mathrm{G}$ as a consequence of the VGT expansion ratio, as it will be shown later on in Figure 11. Comparing plots (a) and (d) in Figure 5 with plots (c) and (d) in Figure 4 it is possible to conclude that the pulse amplitude is not significantly reduced at this location despite of the higher volume upstream of the turbine. Therefore, the pulse amplitude at exhaust manifolds is more influenced by aftertreatment flow restriction than for volume.

In the second measured location (plots (b) and (e)), the pulse amplitude level is again practically the same, regardless of the aftertreatment system element that the flow has crossed. However, mean pressure is reduced at this location in the case of the pre-turbo DPF and DOC configuration since the DPF is causing higher pressure drop. Finally, plots (c) and (f) evidence in comparison to plots (b) and (e) respectively that the reduction of the pulse amplitude is mainly occurring along the first aftertreatment element.

\subsection{Temperature and VGT operating conditions}

Besides the change in aftertreatment pressure drop, the aftertreatment placement upstream of the turbine causes a variation in the temperature profile along the exhaust line that contributes to explain the effects both on aftertreatment and engine performance because of the change in VGT operating conditions.

Figure 6 represents the temperature at the DPF and DOC inlet for every operating point and exhaust line architectures. The temperature corresponding to low load operating points is depicted in plots (a) and (b) for DPF and DOC respectively for the three tested rounds to confirm repeatability. Plots (c) and (d) are referred to DPF and DOC respectively for the operating range of medium-high load. The pre-turbo DOC placement provides an increase of its inlet temperature between $55^{\circ} \mathrm{C}$ and $130^{\circ} \mathrm{C}$ both at low and medium-high load and any the DOC and DPF relative placement. Similar results are obtained in the case of the DPF where in fact an increase of the temperature above $150^{\circ} \mathrm{C}$ is found between pre-turbo and post-turbo placement as the engine load increases.

The increase of the thermal level in the aftertreatment that the pre-turbo aftertreatment configuration provides with respect to the post-turbo placement leads to a noticeable improvement of the conditions for DPF passive regeneration and $\mathrm{CO}$ and $\mathrm{HC}$ conversion efficiency as it will be discussed in Sections 3.4 and 3.5 respectively. The data indicate that the gas temperature across DOC and DPF is above $500^{\circ} \mathrm{C}$ in pre-turbo location for engine loads higher than $30 \%$. At very low load operating points (A and B) the temperature across the aftertreatment is sensitively increased and becomes close to $200^{\circ} \mathrm{C}$ giving as a result $\mathrm{CO}$ and $\mathrm{HC}$ abatement.

The temperature in the tailpipe, i.e. downstream of the DPF and the turbine in a post-turbo and pre-turbo aftertreatment placement respectively, is also relevant since it would affect the SCR/LNT systems to fulfil NOx standards placed at this location (not installed in the tested engine). The results are shown in Figure 7 for the engine operating range tested. Regarding the low load operating points belonging to the NEDC (A to E), which are shown in plot (a), the results confirm a tailpipe temperature increase up to $50^{\circ} \mathrm{C}$ with any pre-turbo aftertreatment configuration and without 
influence of the DOC and DPF relative placement. This value is relevant to improve the NOx conversion efficiency in the low load operating range. However, the results shown in plot (b) related to medium-high load operating points do not present the same trend. In these cases, the pre-turbo aftertreatment placement provides the same or even lower tailpipe temperature than the traditional post-turbo location.

The trend in tailpipe temperature change depending on the exhaust manifold architecture is closely related to the management of the power available in the turbine expansion. Therefore it is related to the previously shown aftertreatment pressure drop but also to VGT position, inlet temperature and expansion ratio. Figure 8 shows these magnitudes for low load operating points A to E any the aftertreatment placement. Figure 8(a) shows that the VGT inlet temperature is slightly lower in the case of a pre-turbo aftertreatment placement being this trend more evident as load increases (from A to E). It is mainly related to the heat loss and pulse lamination across the monoliths which involves the turbine inlet temperature reduction and therefore a reduction of the power available in the VGT. Only a slight dispersion appears in the very low load operating points A and B. The lamination of the pressure pulses demands the VGT to be closer than with the post-turbo aftertreatment placement, as Figure 8(b) shows.

The difference in VGT position with respect to the post-turbo aftertreatment configuration decreases as the engine load increases. This response is due to the fact that the VGT expansion ratio is increasing with engine load, as represented in Figure 8(c). In the case of the post-turbo aftertreatment placement, as load increases the aftertreatment pressure drop also raises with increasing rate as shown in Figure 3. It is negative for available turbine isentropic power and consequently VGT needs to close in order to produce enough power. However, with a pre-turbo aftertreatment placement, the increase of aftertreatment pressure drop is lower in comparison to the post-turbo placement so that the requirements for VGT closing are also lower. Consequently, as load increases the VGT position in pre-turbo and post-turbo placement tends to coincide. Additionally, as the power available in the VGT expansion is increasing, the pulse lamination and temperature drop are losing importance being offset by the improvement in VGT efficiency given by the more open positions and the quasi-steady flow in pre-turbo aftertreatment configurations. This phenomenon is shown in Figure 9, which plots the modelled VGT efficiency corresponding to the operating points F and H. Plots (a) and (b) in Figure 9 represent the comparison between experimental and modelled instantaneous pressure at VGT inlet for post-turbo aftertreatment placement and pre-turbo DPF and DOC configuration. The modelling has been performed with the open-source gas dynamic software OpenWAM [24] whose main characteristics are described in [25] and [26], which details the DPF modelling approach. The comparison evidences the good agreement with experimental data. The complete validation of the engine modelling is described in detail in [21]. Plots (c) and (d) shown in Figure 9 represent the modelled instantaneous VGT efficiency as a function of the blade speed ratio. On one hand, it can be seen that there are an increase of the instantaneous VGT efficiency for the same blade speed ratio when the aftertreatment is placed upstream of the VGT. It is due to the more open position of the VGT as it will be shown in Figure 11(b). On the other hand, the change from pulsating to constant pressure turbocharging gives as a result higher average VGT efficiency. This characteristic can be taken as advantage to match the VGT in order to operate closer to design conditions (maximum efficiency for every VGT position) in most of the engine operating range. 
As the VGT position is controlled to obtain the same boost pressure any the exhaust line configuration, the VGT expansion ratio must be higher in the case of the pre-turbo aftertreatment placement to offset the loss of temperature and pulsating energy. It has effects on the engine back-pressure. In the case of the post-turbo aftertreatment placement, the exhaust manifold pressure is given by the turbine expansion ratio times the addition of ambient pressure and aftertreatment pressure drop. However, in the case of the pre-turbo aftertreatment placement, the multiplicative effect of the expansion ratio on the aftertreatment pressure drop does not exist [19]. This advantage is not enough at low load since the aftertreatment pressure drop is low and its interaction with the VGT is not able to offset the need to increase the expansion ratio to recover the boost pressure. As a consequence, the exhaust manifold pressure results slightly higher for the pre-turbo aftertreatment placement in this operating range, as Figure 10(a) depicts.

The trend observed as engine speed and load increase is corroborated by the experimental results obtained at medium-high load at different engine speeds. Figure 11 represents the VGT operating conditions at these range of load for every of the analysed aftertreatment configurations. Plot (a) shows the temperature at the VGT inlet. The post-turbo aftertreatment configuration presents higher VGT inlet temperature than any of the pre-turbo aftertreatment configurations. Range is between $25^{\circ} \mathrm{C}$ and $55^{\circ} \mathrm{C}$. However, not all this difference is due to heat losses and pulse lamination but also it is related to the VGT position. The temperature at the inlet of the aftertreatment is also represented in the case of the pre-turbo placement in order to provide a figure of the temperature drop in the DPF and DOC. Comparing this temperature with that at the inlet of the VGT in post-turbo aftertreatment configuration (both are gas temperature at exhaust manifold) it can be seen that pre-turbo exhaust manifold temperature is already between $10{ }^{\circ} \mathrm{C}$ and $40^{\circ} \mathrm{C}$ lower than the temperature in post-turbo aftertreatment placement. As the engine is running at the same boost pressure and torque, this temperature difference is on the one hand due to difference in exhaust manifold pressure, which is lower in the case of the pre-turbo aftertreatment configuration as it is shown in Figure 10(b). Reduction reaches up to 0.35 bar. Additionally, equivalence ratio is also lower because of the lower fuel consumption, as it will be shown in Section 3.3, leading to lower exhaust manifold temperature.

On the one hand, the first reason for the exhaust manifold pressure reduction is the change in aftertreatment pressure drop. At medium-high load the aftertreatment pressure drop is high and very sensitive to the pre-turbo placement. It brings an important reduction, mainly as engine speed (mass flow) increases, as shown in Figure 3(b). On the other hand, the second reason is that such a pressure drop is not multiplied by the expansion ratio to set the engine back-pressure but added to it. Since the pressure drop is high in this operating range, this effect governs the exhaust manifold pressure, which becomes lower in the case of the pre-turbo aftertreatment configurations.

In fact, the increasing aftertreatment pressure drop is very negative for turbine isentropic power in the case of post-turbo aftertreatment placement. In this configuration the VGT is much more sensitive to aftertreatment pressure drop than in pre-turbo aftertreatment configurations [19]. Thus, Figure 11(b) shows that the VGT position is even more closed in the post-turbo than in the pre-turbo aftertreatment placements. Despite this, the expansion ratio, which is represented in Figure 11(c), is higher in the case of the pre-turbo aftertreatment placement, any the DPF and DOC 
relative position. These settings have been managed by the ECU to ensure the boost control with available power upstream of the turbine.

\subsection{Engine performance}

Figure 12 and 13 show the corrected bsfc variation that the pre-turbo aftertreatment configuration provides as a function of the steady-state operating range, low and medium-high load respectively. Correction of bsfc has been performed according to standard ISO/DIS 1585 [27]. The bsfc variation is calculated taking as reference the postturbo aftertreatment configuration. The differences in bsfc between both configurations are directly related to the change in pumping losses so that the results in bsfc present the same fashion as that shown in Figure 10 concerning the exhaust manifold pressure.

Figure 12 shows that at low load there is a penalty in bsfc. According to the discussion in Section 3.1, the penalty in fuel economy decreases as the engine load increases, from operating points A and B (7\% and 5\% of load respectively) to operating points $\mathrm{D}$ and $\mathrm{E}$ ( $33 \%$ and $30 \%$ of load respectively). There is not evident influence of the relative aftertreatment placement in pre-turbo configuration. Despite of this clear trend, conclusions on the quantitative variation in fuel economy are complex since in this range of operation the measurement of the bsfc results very inaccurate. It is due to the combination of the error in the measurement of power (torque) and fuel consumption. Hence the high lack of repeatability in operating points A, B and C. Black bands in Figure 12 represent the error in percentage bsfc difference. The error in bsfc difference has been calculated according to [28]:

$$
\begin{gathered}
e_{b s f c}=b s f c \sqrt{\left(\frac{e_{\dot{m}_{f}}}{\dot{m}_{f}}\right)^{2}+\left(\frac{e_{P}}{P}\right)^{2}} \\
e_{\frac{\Delta b s f c}{b s f c_{p o s t}}}=\frac{\Delta b s f c}{b s f c_{\text {post }}} \sqrt{\left(\frac{e_{b s f c_{p r e}}}{b s f c_{p r e}-b s f c_{\text {post }}}\right)^{2}+\left(\frac{b s f c_{p r e} e_{b s f c_{p o s t}}}{b s f c_{\text {post }}\left(b s f c_{\text {pre }}-b s f c_{\text {post }}\right)}\right)^{2}}
\end{gathered}
$$

In eq. $1 e_{b s f c}$ represents the error in the bsfc measurement, which is a function of the bsfc, the fuel mass flow ( $\left.\dot{m}_{f}\right)$, the power $(P)$, the error in fuel mass flow measurement $\left(e_{\dot{m}_{f}}\right)$ and the error in power measurement $\left(e_{P}\right)$. Finally, eq. 2 provides the error in percentage bsfc difference $\left(e_{\frac{\Delta b s f c}{b s f c p o s t}}\right)$.

The trend in fuel economy improvement as load increases is observed in Figure 13. It is obtained an important fuel saving in the pre-turbo aftertreatment configuration, which ranges from $3 \%$ to $6 \%$. In this case, the measurement of these operating points results accurate being the error in bsfc difference reduced in comparison with the bsfc variation. These results confirm the great benefit of pre-turbo aftertreatment configurations in terms of fuel economy when the engine operates at medium-high load.

\subsection{DPF passive regeneration}

The capability of pre-turbo aftertreatment configurations to improve the performance of the DPF in terms of passive regeneration has been assessed by measuring the steady-state operating points of low load (A to E) in rounds. 
The operating points have been tested in different order in every round to evaluate its influence on the total soot mass regenerated.

Figure 14 compares the collected soot mass in the DPF during every round against the soot accumulated in the DPF at the end of the round. The collected soot mass during every round is calculated from the measurement of the soot opacity upstream and downstream of the DPF in every operating point [29]. The soot accumulated at the end of the round is obtained according to the weighing procedure applied before and after the test described in Section 2.2. Although the application of empirical correlations non-based on mass evaluation can be a source of uncertainty, the tests are the same in all the aftertreatment configurations. Therefore the procedure is considered suitable for comparison proposals, i.e. to estimate the mass of regenerated soot in every round and aftertreatment placement. Note that Figure 14 clearly indicates that the emitted soot mass is almost the same in all rounds and aftertreatment configurations.

Table 5 details the mass of regenerated soot in every round as a function of the DPF placement. It is obtained as the difference between collected along the test and remaining at the end. Figure 14(a) shows that with a standard post-turbo aftertreatment placement the difference between soot mass collected along the test and finally accumulated is very reduced. The results detailed in Table 5 indicate that the soot mass regenerated is between $1.1 \mathrm{~g}$ and $2.7 \mathrm{~g}$ which represents a range of $10.3 \%$ to $25.7 \%$ of the soot mass collected by the DPF.

It is interesting to note that the soot mass regenerated increases from Round 1 to Round 3, although the soot mass collected in all of them can be assumed to be the same. This response is due to the order in which the operating points are tested during the round. In the first round the operating point tested in first place is E, which is characterized by the higher soot raw emission and exhaust gas temperature. Due to the fact that the engine warm-up is carried out during its testing, the thermal transient process results long because of the initial cold wall conditions. In addition, the DPF is initially clean. Consequently passive regeneration does not take place. These conditions lead to low rates of soot oxidation despite of the exhaust gas temperature. In the following rounds, the operating point $\mathrm{E}$ is tested in last place. It makes that when point $\mathrm{E}$ starts to be tested soot mass is already accumulated in the DPF. Additionally the duration of the thermal transient process is reduced in time since wall temperature is stabilised according to the previously tested operating point. As a result, Round 2 and Round 3 provide an important increase of the mass of soot regenerated for all the evaluated configurations.

The influence of the DPF thermal transient on the passive regeneration is manifested in the comparison between Round 2 and Round 3. In Round 2 the operating point $\mathrm{D}$, which is the second one with greater exhaust gas temperature, is placed in first place whereas in Round 3 is located in fourth place, i.e. just before the operating point E. Therefore, this placement is contributing to accelerate the thermal transient corresponding to operating point $\mathrm{E}$. Hence the increase in regenerated soot mass between Round 2 and Round 3.

This behaviour is also found when testing the pre-turbo aftertreatment configurations. However, this placement is providing an important improvement in passive regeneration conditions. Plots (b) and (c) in Figure 14 shows that with pre-turbo aftertreatment placement the collected soot mass in the DPF is very similar to that collected in post- 
turbo aftertreatment configuration. However, the mass of soot remaining in the DPF at the end of every round is very reduced in comparison with the post-turbo aftertreament placement.

The pre-turbo DOC\&DPF configuration provides a regeneration ranging between $6.3 \mathrm{~g}$ and $10.5 \mathrm{~g}$ from Round 1 to Round 3, which represent $56.6 \%$ to $92.3 \%$ of the collected soot mass in the DPF. Similar results are obtained in the case of a DPF\&DOC relative placement in pre-turbo configuration, although with a slight decrease in regenerated soot mass in Round 1 (50.1\%) and Round 3 (89.7\%). However this configuration provides the maximum regenerated soot mass for Round 2 of all of tested configurations (80.3\%). The reduction that is found in Round 1 and Round 3 with pre-turbo DPF\&DOC configuration with respect to pre-turbo DOC\&DPF configuration is due to the fact that the soot oxidation is being not favoured by the generation of $\mathrm{NO}_{2}$ in the DOC because it is placed downstream of the DPF. However, this effect is offset in Round 2 with the improvement of the thermal transient process that takes places before testing operating point $\mathrm{E}$. As previously explained, operating point $\mathrm{E}$ is tested in last place involving a longer thermal transient evolution from operating point $\mathrm{A}$, which has the lowest exhaust gas temperature. The placement of the DPF upstream of the DOC accelerates such a transient what is becoming more important than the $\mathrm{NO}_{2}$ content in comparison with pre-turbo DOC\&DPF configuration. As a result, the conditions for passive regeneration are improved in Round 2.

At medium-high loads (operating points $\mathrm{F}$ to $\mathrm{K}$ ), the high thermal level upstream of the turbine ensures the complete DPF passive regeneration under steady-state operating conditions (15 min testing every operating point) with pre-turbo aftertreatment configuration. Table 6 points out that the soot accumulated in the DPF at the end of every test is negligible. The post-turbo aftertreatment configuration provides similar results in this operating region. Only operating points I and $\mathrm{K}$ appear as exception since certain level of soot accumulation was found once finished the test.

The results are showing how an engine with a pre-turbo aftertreatment configuration operating under steady-state conditions at low engine loads (below 30\%) is able to reach high rates of passive regeneration. If the engine load raises over 50\%, what ensures DPF passive regeneration, it is possible to oxidise previous soot mass loading without the need to resort to fuel damaging active regeneration strategies.

\subsection{Engine emissions}

Pre-turbo aftertreatment configuration is providing continuous regeneration at steady-state conditions. This advantage is obtained at the same time that the filtration efficiency is kept comparable to that obtained in post-turbo aftertreatment placement. The filtration efficiency has been calculated according to eq. 3 from particle concentration obtained with the EEPS system:

$$
E_{f}=100\left(1-\frac{c_{d o w n}}{c_{u p}}\right)
$$

In eq. $3 c_{d o w n}$ and $c_{u p}$ are the particle concentration downstream and upstream of the DPF respectively. 
Plot (a) in Figure 15 shows the filtration efficiency corresponding to the low load operating points tested in Round 1. No differences are found in DPF filtration efficiency in this operating range with pre-turbo DPF placement ensuring filtration efficiency close to $100 \%$.

Figure 15(b) depicts the particle size distribution upstream of the DPF for post-turbo and pre-turbo DOC\&DPF placement. In all the operating points the raw soot emission is very similar in particle size distribution and concentration between post-turbo and pre-turbo aftertreatment configurations. Further detail on the analysis of soot emissions can be found in the work of Bermúdez et al. [30], which is dedicated to the study of engine emissions with pre-turbo aftertreatment placement.

As a complement to the information provided by the computation of the filtration efficiency, Figure 16 shows the opacity downstream of the DPF as a function of the aftertreatment placement for every operating point. Figure 16(a) represents the opacity corresponding to the operating points of low load. Opacity measurement in post-turbo aftertreatment placement and both pre-turbo aftertreatment configurations shows repeatability among the different rounds and in all case is below $1.5 \%$. The same result is obtained from the analysis of the opacity at medium-high loads any the engine speed, which is represented in Figure 16(b). Opacity is ranging below 2\% in all the different aftertreatment configurations.

The regulated tailpipe gas emissions as a function of the aftertreatment placement are shown in Figure 17, which is devoted to low load operating points, and Figure 18, which regards to medium-high load operating points. Focusing on the low load range, Figure 17(a) shows that $\mathrm{NO}_{\mathrm{x}}$ emissions result similar between post-and pre-turbo aftertreatment configurations.

The higher thermal level upstream of the aftertreatment benefits the $\mathrm{CO}$ and $\mathrm{HC}$ conversion efficiency in the DOC. This benefit is especially noticeable at very low load, such as operating point A. Figure 17(b), which represents CO emissions, and Figure 17(c), which is devoted to HC emissions, shows how a pre-turbo DOC placement contributes to increase the conversion efficiency at operating point A. Figure 17(b) points out that the pre-turbo aftertreatment placement abates the CO raw emission any the DOC\&DPF relative placement. However, the abatement is not possible in operating point A with a post-turbo DOC placement, even making use of a close-coupled DOC and an underfloor DOC. It is important to note that the tailpipe emissions with a pre-turbo configuration are the same or lower even with less catalytic surface, because the close-coupled DOC has been removed in these configurations. The same conclusions are obtained from the analysis of the $\mathrm{HC}$ emissions corresponding to the operating point $\mathrm{A}$. Abatement is not complete in this operating point with post-turbo aftertreatment placement in contrast to the lower emission exhibited by any of the pre-turbo DOC placements.

Finally, Figure 18 confirms these conclusions in the medium-high load operating range. Tailpipe $\mathrm{NO}_{\mathrm{x}}$ emissions are unaffected by the aftertreatment placement. The same result is obtained concerning $\mathrm{CO}$ and $\mathrm{HC}$ emissions, which are below $5 \mathrm{ppm}$ for most operating points any the DOC placement because of the high exhaust gas temperature. 


\section{Summary and conclusions}

An experimental study of pre-turbo aftertreatment configuration has been presented to evaluate the impact of this kind of architecture on a turbocharged Diesel engine for passenger car applications. The analysis has concerned the engine operation, performance and emissions comparing with the traditional post-turbo aftertreatment configuration. The whole work is divided into two parts being this first part focused on steady-state operating conditions.

Two pre-turbo aftertreatment architectures have been considered depending on the relative DOC and DPF placement; the objective is to include the influence of the pre-turbo DPF and DOC configuration as a way to protect the turbine with a high cell density metallic DOC. The original engine calibration for combustion settings has been applied in every of the exhaust line configurations. Only the VGT position settings have been modified in the EGR engine operating range to ensure the same boost pressure in pre-turbo and post-turbo cases.

The testing range is covering the low load operating conditions with points selected from the NEDC and the medium-high load range at different engine speeds. This distinction has allowed assessing how behaves the balance between the benefit in aftertreatment pressure drop magnitude and location that the pre-turbo aftertreatment configuration provides and the drawbacks regarding reduction of temperature and pulse energy at the VGT inlet with respect to the post-turbo aftertreatment placement.

At the low engine load and speed operating region, the reduction in aftertreatment pressure drop and the fact that it is not multiplied by the expansion to set the engine back-pressure is not able to compensate the heat losses and the flow lamination across the aftertreatment system in pre-turbo placement. As a consequence, the VGT is closer in pre-turbo aftertreatment configurations and the increase in expansion ratio leads to slightly higher exhaust manifold pressure. Hence a damage in fuel consumption is obtained although it becomes reduced as the engine load increases. This trend has been clearly confirmed with the analysis of the medium-high load operating points; the high reduction in aftertreatment pressure drop is governing the improvement of the engine performance. It shows a reduction between $3 \%$ and $6 \%$ in bsfc depending on the operating point and the relative placement of DOC and DPF. In fact, although engine operation is not highly affected by the position of DOC with respect to the DPF in pre-turbo placement, better engine performance is found with a pre-turbo DPF and DOC configuration. Although obtained in a passenger car engine, this result at medium-high load would be of special interest for the application of pre-turbo aftertreatment aftertreatment architectures in heavy-duty engines, usually working at higher load than light duty engines.

Concerning DOC performance, the significant increase of the thermal level across the aftertreatment systems has lead to an increase of the $\mathrm{CO}$ and $\mathrm{HC}$ conversion efficiency at very low load with pre-turbo DOC placement. This result has been achieved with a reduction of the catalyst surface since the close-coupled DOC used in the post-turbo aftertreatment configuration was removed for pre-turbo evaluation. It confirms the potential of pre-turbo aftertreatment configuration for volume reduction and cost savings in aftertreatment manufacturing.

As regards DPF performance, no differences have been found in soot emission, with opacity and particle concentration measurements. Overall filtration efficiency is not affected by the DPF placement. However a noticeable 
improvement of the passive regeneration capability is obtained in comparison to the post-turbo DPF placement. Low load operating points have been tested in rounds with different order. Results points out that passive regeneration is depending on the operating point order because of the thermal transient influence. Under transient operation it means dependence on the driving cycle. However, the regenerated soot mass with pre-turbo DPF placement has ranged between $50 \%$ and $92 \%$ of the total collected mass of soot. It contrasts with the post-turbo aftertreatment configuration, which was only able to oxidise passively between $10 \%$ and $25 \%$ of the collected mass of soot. The placement of the DPF downstream of the DOC provides a slightly higher rate of oxidation than the proposed DPF\&DOC placement due to the $\mathrm{NO}_{2}$ benefit. Anyway it is very dependent on the thermal transient evolution which may even drift the effect of the $\mathrm{NO}_{2}$ besides the existence of additional alternatives such as small pre-DOC in exhaust ports/manifold followed by the main DPF\&DOC core.

\section{Acknowledgements}

This work has been partially supported by the Vicerrectorado de Investigación de la Universitat Politènica de València through grant number SP20120340-UPPTE/2012/96 and by the Conselleria de Educació, Cultura i Esport of the Generalitat Valenciana through grant number GV/2013/043.

\section{References}

[1] Knecht W. Diesel engine development in view of reduced emission standards, Energy 2008;33:264-71.

[2] Marelli S, Capobianco M. Steady and pulsating flow efficiency of a waste-gated turbocharger radial flow turbine for automotive application, Energy 2011;36:459-65.

[3] Ishikawa N. A study on emissions improvement of a Diesel engine equipped with a mechanical supercharger, Int J Engine Res 2012;13:99107.

[4] Galindo J, Serrano JR, Climent H, Varnier O. Impact of two-stage turbocharging architectures on pumping losses of automotive engines based on an analytical model, Energy Convers Manag 2010;51:1958-69.

[5] Lapuerta M, Rodríguez-Fernández J, Oliva F. Effect of soot accumulation in a diesel particle filter on the combustion process and gaseous emissions, Energy 2012;47:543-52.

[6] Jaichandar S, Annamalai K. Combined impact of injection pressure and combustion chamber geometry on the performance of a biodiesel fueled diesel engine, Energy 2013;55:330-9.

[7] Yu B, Kum S, Lee C, Lee S. Effects of exhaust gas recirculation on the thermal efficiency and combustion characteristics for premixed combustion system, Energy 2013;49:375-83.

[8] Windsor RE, Baumgard KJ. Internal combustion engine with dual particulate traps ahead of turbocharger, Patent US 2009/0151328 A1, United States. (February 2009).

[9] Payri F, Desantes JM, Galindo J, Serrano JR. Exhaust manifold of a turbo-supercharged reciprocating engine, Patent WO2010092201A1. Priority date 13/02/2009. European Patent Office, (2010).

[10] Reizig M, Brück R, Konieczny R, Treiber P. New approaches to catalyst substrate application for Diesel engines, in: SAE Technical Paper 2001-01-0189, 2001.

[11] Carberry B, Grasi G, Guerin S, Jayat F, Konieczny R. Pre-turbocharger catalyst - fast catalyst light-off evaluation, in: SAE Technical Paper 2005-01-2142, 2005. 
[12] Joergl V, Keller P, Weber O, Mueller-Hass K, Konieczny R. Influence of pre turbo catalyst design on Diesel engine performance, emissions and fuel economy, in: SAE Technical Paper 2008-01-0071, 2008.

[13] Hiereth H. Daimler-Benz AG car test with a free-running pressure-wave charger - A study for an advanced supercharging system, in: SAE Technical Paper 890453, 1989.

[14] Khair M. A review of diesel particulate filter technologies, in: SAE Technical Paper 2003-01-2303, 2003.

[15] Payri F, Desantes JM, Piqueras P, Serrano JR. Device for treating exhaust gases from diesel turbo-supercharged reciprocating internal combustion engines (RICE), Patent WO 2013/041747 A1. Priority date 23/09/2011. European Patent Office, (2013).

[16] Subramaniam MN, Joergl V, Keller P, Weber O, Toyoshima T, Vogt CD. Feasibility assessment of a pre-turbo after-treatment system with a 1D modeling approach, in: SAE Technical Paper 2009-01-1276, 2009.

[17] Brüstle C, Downey M, Subramaniam MN, Birckett A, Tomazic D. Aftertreatment in a pre-turbo position: size and fuel consumption advantage for Tier 4 large-bore Diesel engines, in: Aachen Colloquium Automobile and Engine Technology 2011, Aachen, Germany, 2011.

[18] Bermúdez V, Serrano JR, Piqueras P, García-Afonso O. Assessment by means of gas dynamic modelling of a pre-turbo diesel particulate filter configuration in a turbocharged HSDI Diesel engine under full-load transient operation, Proc Inst Mech Eng Part D-J Automob Eng 2011;225(9):1134-55.

[19] Bermúdez V, Serrano JR, Piqueras P, García-Afonso O. Influence of DPF soot loading on engine performance with a pre-turbo aftertreatment exhaust line, in: SAE Technical Paper 2012-01-0362, 2012.

[20] Payri F, Serrano JR, Piqueras P, García-Afonso O. Performance analysis of a turbocharged heavy duty Diesel engine with a pre-turbo diesel particulate filter configuration, SAE Int J Engines 2011;4(2):2559-72.

[21] Serrano JR, Guardiola C, Piqueras P, Angiolini E. Analysis of the aftertreatment sizing for pre-turbo DPF and DOC exhaust line configuration, in: SAE Technical Paper 2014-01-1498.

[22] Serrano JR, Arnau FJ, Dolz V, Piqueras P. Methodology for characterization and simulation of turbocharged Diesel engines combustion during transient operation. Part 1: Data acquisition and post-processing, Appl Therm Eng 2009;29(1):142-9.

[23] Luján JM, Galindo J, Serrano JR, Pla B. A methodology to identify the intake charge cylinder-to-cylinder distribution in turbocharged direct injection Diesel engines, Meas Sci Technol 2008;19:065401.

[24] Openwam website, CMT-Motores Térmicos (Universitat Politècnica de València). www.openwam.org (2014).

[25] Galindo J, Serrano JR, Arnau FJ, Piqueras P. Description of a Semi-Independent Time Discretization methodology for a one-dimensional gas dyanmics model, J Eng Gas Turb Power 2009;131:034504.

[26] Torregrosa AJ, Serrano JR, Arnau FJ, Piqueras P. A fluid dynamic model for unsteady compressible flow in wall-flow diesel particulate filters, Energy 2011;36:671-84.

[27] ISO International Organization for Standardization, Road vehicles - Engine test code - Net power, ISO/DIS 1585, 1992.

[28] Joint Committee for Guides in Metrology, Evaluation of measurement data - Guide to the expression of uncertainty in measurement (GUM), JCGM 100:2008

[29] Bermúdez V, Luján JM, Serrano JR, Pla B. Transient particle emission measurement with optical techniques, Meas Sci Technol 2008; 19:0654004.

[30] Bermúdez V, Luján JM, Piqueras P, Campos D. Pollutants emission and particle behavior in a pre-turbo aftertreatment light-duty Diesel engine, Energy 2014;66:509-22.

\section{Nomenclature}

\footnotetext{
$c_{\text {down }}$ particle concentration downstream of the DPF

$c_{u p} \quad$ particle concentration upstream of the DPF
} 


$\begin{array}{ll}e_{b s f c} & \text { error in bsfc } \\ e_{\dot{m}_{f}} & \text { error in fuel mass flow } \\ e_{P} & \text { error in power } \\ e_{\frac{\Delta b s f c}{b s f c_{p o s t}}} & \text { error in percentage bsfc difference } \\ E_{f} & \text { filtration efficiency } \\ k_{w} & \text { porous wall permeability } \\ \dot{m}_{f} & \text { fuel mass flow } \\ P & \text { power } \\ T & \text { temperature }\end{array}$

Greek letters

$\Delta$

difference

$\begin{array}{ll}\text { Abbreviations } & \\ \text { bsfc } & \text { brake specific fuel consumption } \\ \text { DOC } & \text { diesel oxidation catalyst } \\ \text { DPF } & \text { diesel particulate filter } \\ \text { EGR } & \text { exhaust gas recirculation } \\ \text { LNT } & \text { lean } \mathrm{NO}_{\mathrm{x}} \text { trap } \\ \text { NEDC } & \text { New European Driving Cycle } \\ \text { SCR } & \text { selective catalytic reduction } \\ \text { VGT } & \text { variable geometry turbine }\end{array}$

\section{List of Tables}

- Table 1.- Main characteristics of the engine.

- Table 2.- Characteristics of the instrumentation.

- Table 3.- Main characteristics of the aftertreatment systems.

- Table 4.- Definition of the tested steady-state operating points.

- Table 5.- Regenerated soot mass in every round as a function of the aftertreatment placement at low load operating points.

- Table 6.- Soot mass accumulated in the DPF at the end of the test of medium-high load operating points for every aftertreatment placement.

\section{List of Figures}

- Figure 1.- Scheme of the tested exhaust line architectures.

- Figure 2.- Steady-state operating points selected from NEDC. 
- Figure 3.- Pressure drop across the aftertreatment as a function of the aftertreatment configuration and the steady-state operating point.

- Figure 4.- Instantaneous VGT inlet pressure as a function of the aftertreatment configuration and the steady-state operating point.

- Figure 5.- Instantaneous pressure along the aftertreatment elements as a function of the pre-turbo aftertreatment configuration.

- Figure 6.- DPF and DOC inlet temperature as a function of the aftertreatment configuration and the steady-state operating point.

- Figure 7.- Tailpipe gas temperature as a function of the aftertreatment configuration and the steady-state operating point.

- Figure 8.- VGT operating conditions as a function of the aftertreatment configuration and the steady-state operating point at low engine load.

- Figure 9.- Modelled instantaneous VGT inlet pressure and VGT efficiency as a function of the aftertreatment configuration in operating points $\mathrm{F}$ and $\mathrm{H}$.

- Figure 10.- Exhaust manifold pressure as a function of the aftertreatment configuration and the steady-state operating point.

- Figure 11.- VGT operating conditions as a function of the aftertreatment configuration and the steady-state operating point at medium-high load.

- Figure 12.- Variation in bsfc due to the pre-turbo aftertreatment placement: operating points of low load.

- Figure 13.- Variation in bsfc due to the pre-turbo aftertreatment placement: operating points of medium-high load.

- Figure 14.- Collected soot mass against soot mass remaining in the DPF as a function of the aftertreatment placement and round.

- Figure 15.- a) DPF filtration efficiency based on particle concentration; b) Raw particle concentration against particle size distribution as a function of the aftertreatment configuration and the steady-state operating points at low engine load.

- Figure 16.- Tailpipe opacity as a function of the aftertreatment configuration and the engine operating point.

- Figure 17.- Regulated tailpipe gas emissions as a function of the aftertreatment configuration and the engine operating point at low load.

- Figure 18.- Regulated tailpipe gas emissions as a function of the aftertreatment configuration and the engine operating point at medium-high load. 
Table 1: Main characteristics of the engine.

\begin{tabular}{ll}
\hline \hline Type & HSDI Diesel passenger car engine \\
Displacement & $1,997 \mathrm{~cm}^{3}$ \\
Bore & $85 \mathrm{~mm}$ \\
Stroke & $88 \mathrm{~mm}$ \\
Number of cylinders & 4 in line \\
Number of valves & 4 per cylinder \\
Compression ratio & $18: 1$ \\
Maximum power @ speed & $100 \mathrm{~kW} @ 4,000 \mathrm{rpm}$ \\
Maximum torque @ speed & $320 \mathrm{Nm} @ 1,750 \mathrm{rpm}$ \\
\hline \hline
\end{tabular}

Table 2: Characteristics of the instrumentation.

\begin{tabular}{llll}
\hline \multicolumn{1}{c}{ Magnitude } & \multicolumn{1}{c}{ Sensor/Instrument } & Range & \multicolumn{1}{c}{ Error } \\
\hline Temperature & Thermocouple Type K & {$\left[-200-1,200^{\circ} \mathrm{C}\right]$} & $\pm 1.1^{\circ} \mathrm{C} \mathrm{or} 0.4 \%$ (actual value) \\
Mean pressure & Piezoresistive PMA P40 & {$[0-6 \mathrm{bar}]$} & $\pm 0.3 \%$ (full scale) \\
Instantaneous pressure & Piezoresistive Kistler 4045 & {$[0-5 \mathrm{bar}]$} & $\pm 0.1 \%$ (full scale) \\
Fuel mass flow & Gravimetric balance & {$[0-27 \mathrm{~kg} / \mathrm{h}]$} & $\pm 0.12 \%$ (full scale) \\
Air mass flow & Sensyflow ABB FMT700-P & {$[0-720 \mathrm{~kg} / \mathrm{h}]$} & $\pm 1 \%$ (actual value) \\
Torque & Torquimeter & {$[-650-650 \mathrm{Nm}]$} & $\pm 0.1 \%$ (full scale) \\
Turbocharger speed & Picoturn-SM5.3 & {$[200-400,000 \mathrm{rpm}]$} & $\pm 0.25 \%$ (full scale) \\
DPF weight & A\&D Weighing GX-20K & {$[0-21 \mathrm{~kg}]$} & $\pm 1 \mathrm{~g}$ (full scale) \\
\hline \hline
\end{tabular}

Table 3: Main characteristics of the aftertreatment systems.

\begin{tabular}{lclc}
\hline \multicolumn{1}{c}{ DOC } & \multicolumn{2}{c}{ DPF } \\
\hline Diameter [mm] & 145 & Diameter [mm] & 135 \\
Length [mm] & 105 & Effective length [mm] & 165 \\
Volume [1] & 1.73 & Plug length [m] & 0.005 \\
Cell density [cpsi] & 400 & Volume [1] & 2.43 \\
Cell size [mm] & 0.94 & Cell density [cpsi] & 200 \\
Wall thickness [mm] & 0.33 & Cell size [mm] & 1.47 \\
$\mathrm{~N}^{\mathrm{o}}$ of channels [-] & 10,240 & Wall thickness [mm] & 0.32 \\
Catalytic area [m $\left.{ }^{2}\right]$ & 4.04 & $\mathrm{~N}^{\mathrm{o}}$ of channels [-] & 4,470 \\
& & Filtration area [m $\left.{ }^{2}\right]$ & 2.17 \\
& & $k_{w}\left[\mathrm{~m}^{2}\right]$ & $3.85 \times 10^{-13}$ \\
\hline \hline
\end{tabular}


Table 4: Definition of the tested steady-state operating points.

\begin{tabular}{ccccc}
\hline \hline Point & $\begin{array}{c}\text { Speed } \\
{[\mathrm{rpm}]}\end{array}$ & $\begin{array}{c}\text { Load } \\
{[\%]}\end{array}$ & $\begin{array}{c}\text { EGR rate } \\
{[\%]}\end{array}$ & $\begin{array}{c}\text { DPF inlet T } \\
\text { (post-turbo) }\left[{ }^{\circ} \mathrm{C}\right]\end{array}$ \\
\hline $\mathrm{A}$ & 1,370 & 7 & 48.5 & 105 \\
$\mathrm{~B}$ & 1,960 & 5 & 36 & 153 \\
$\mathrm{C}$ & 1,580 & 15 & 36.5 & 187 \\
$\mathrm{D}$ & 1,660 & 34 & 14 & 354 \\
$\mathrm{E}$ & 2,240 & 31 & 13 & 389 \\
\hline $\mathrm{F}$ & 1,500 & 90 & - & 456 \\
$\mathrm{G}$ & 2,000 & 80 & - & 474 \\
$\mathrm{H}$ & 2,500 & 80 & - & 487 \\
$\mathrm{I}$ & 3,000 & 70 & - & 462 \\
$\mathrm{~J}$ & 3,500 & 70 & - & 451 \\
$\mathrm{~K}$ & 4,000 & 50 & - & 461 \\
\hline \hline
\end{tabular}

Table 5: Regenerated soot mass in every round as a function of the aftertreatment placement at low load operating points.

\begin{tabular}{cccc}
\hline \hline Round & $\begin{array}{c}\text { Post-turbo } \\
{[\mathrm{g}]}\end{array}$ & $\begin{array}{c}\text { Pre-turbo DOC\&DPF } \\
{[\mathrm{g}]}\end{array}$ & $\begin{array}{c}\text { Pre-turbo DPF\&DOC } \\
{[\mathrm{g}]}\end{array}$ \\
\hline 1 & $1.1(10.3 \%)$ & $6.3(56.6 \%)$ & $5.5(50.1 \%)$ \\
2 & $2.3(21.1 \%)$ & $8.3(71.7 \%)$ & $9.3(80.3 \%)$ \\
3 & $2.7(25.7 \%)$ & $10.5(92.3 \%)$ & $10.2(89.7 \%)$ \\
\hline \hline
\end{tabular}

Table 6: Soot mass accumulated in the DPF at the end of the test of medium-high load operating points for every aftertreatment placement.

\begin{tabular}{cccc}
\hline \hline Point & $\begin{array}{c}\text { Post-turbo } \\
{[\mathrm{g}]}\end{array}$ & $\begin{array}{c}\text { Pre-turbo DOC\&DPF } \\
{[\mathrm{g}]}\end{array}$ & $\begin{array}{c}\text { Pre-turbo DPF\&DOC } \\
{[\mathrm{g}]}\end{array}$ \\
\hline $\mathrm{F}$ & 0.6 & 0.1 & 0.2 \\
$\mathrm{G}$ & 0.1 & 0 & 0.1 \\
$\mathrm{H}$ & 0.7 & 0.3 & 0 \\
$\mathrm{I}$ & 0.1 & 0.5 & 0.3 \\
$\mathrm{~J}$ & 1.6 & 0.3 & 0.4 \\
$\mathrm{~K}$ & 4.8 & 0 & 0.1 \\
\hline \hline
\end{tabular}


a)

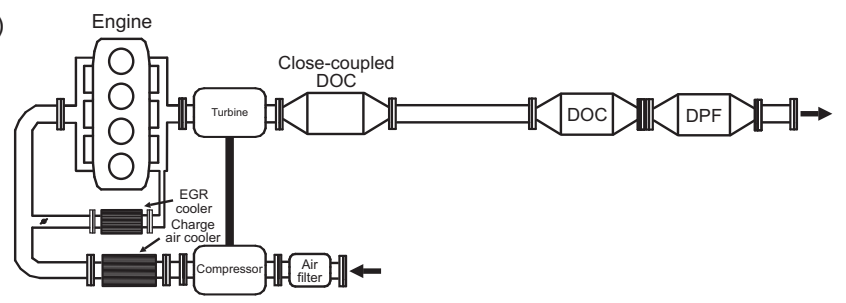

b)

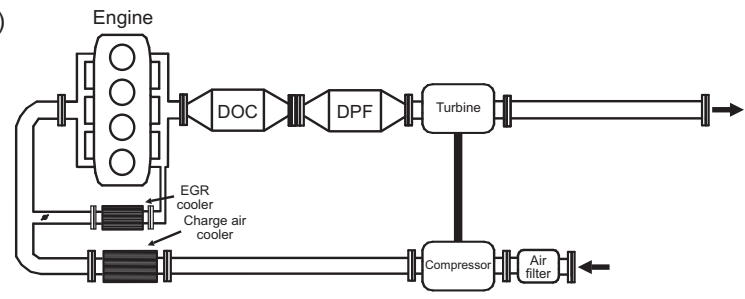

c)

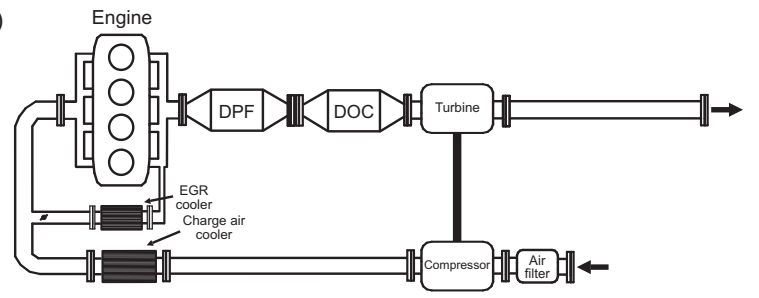

Figure 1: Scheme of the tested exhaust line architectures.

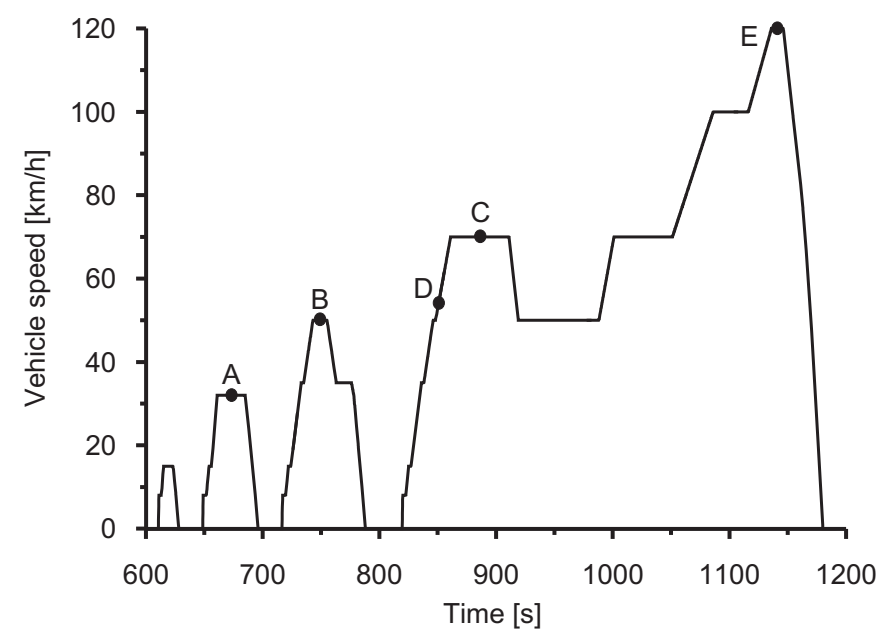

Figure 2: Steady-state operating points selected from NEDC. 


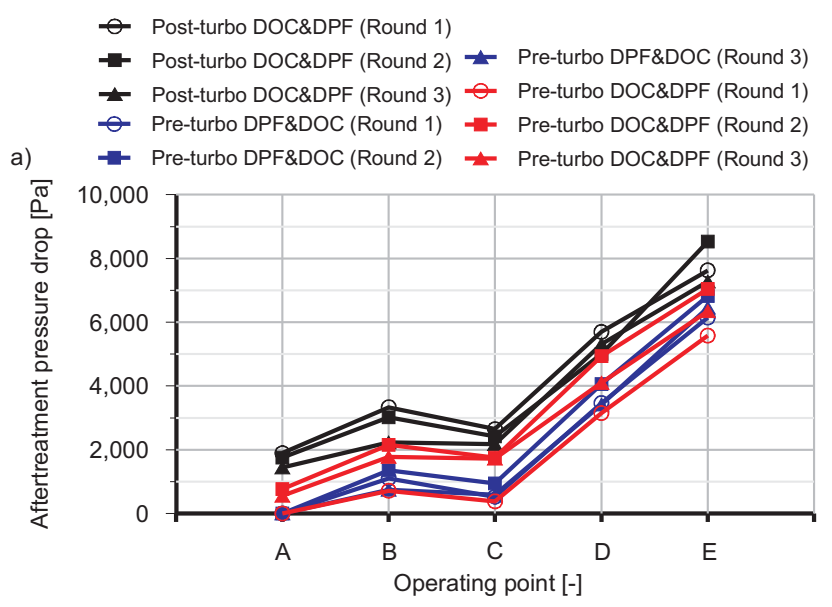

b) $\rightarrow$ Post-turbo DOC\&DPF $\rightarrow$ Pre-turbo DPF\&DOC $\rightarrow$ Pre-turbo DOC\&DPF

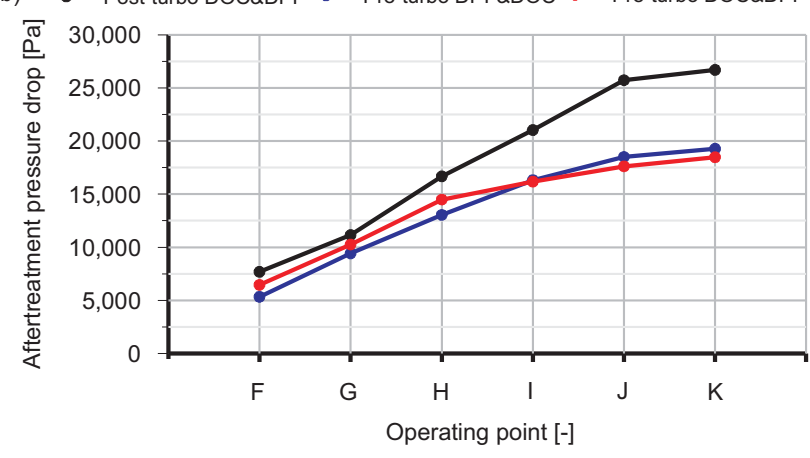

Figure 3: Pressure drop across the aftertreatment as a function of the aftertreatment configuration and the steady-state operating point. 

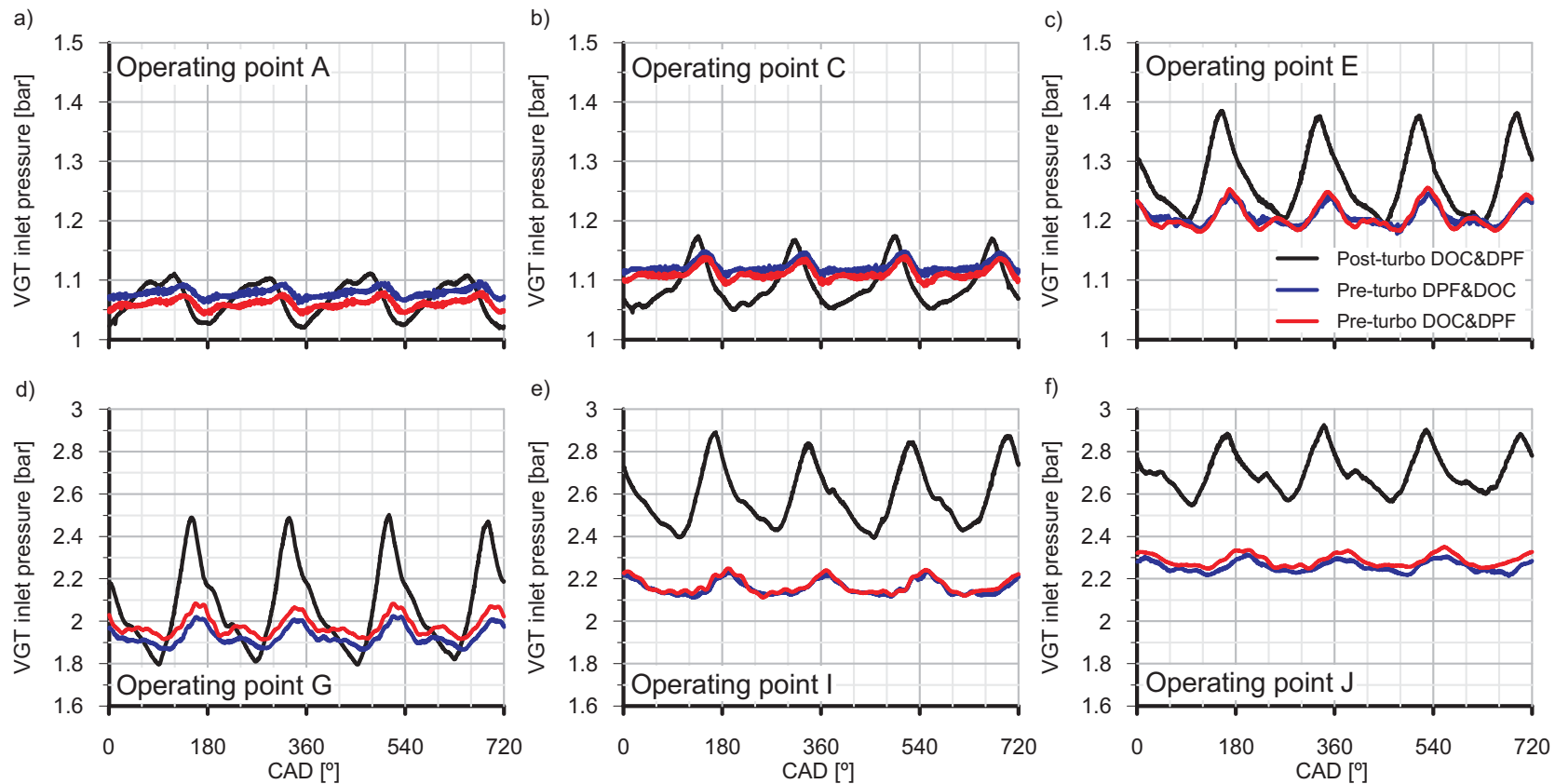

Figure 4: Instantaneous VGT inlet pressure as a function of the aftertreatment configuration and the steady-state operating point.
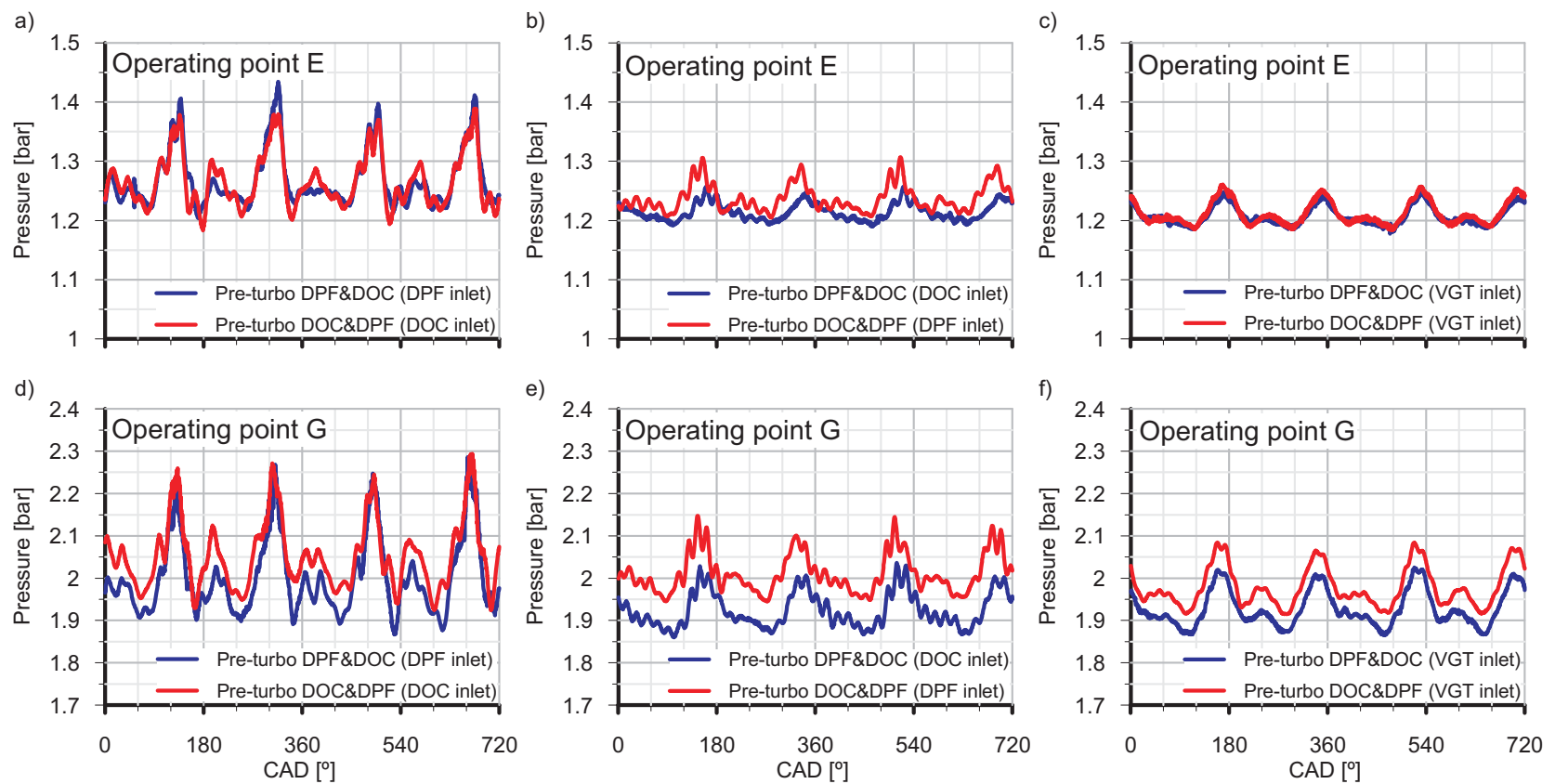

Figure 5: Instantaneous pressure along the aftertreatment elements as a function of the pre-turbo aftertreatment configuration. 


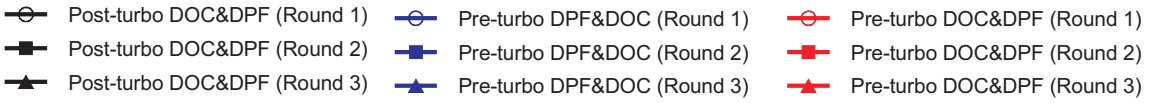

a)
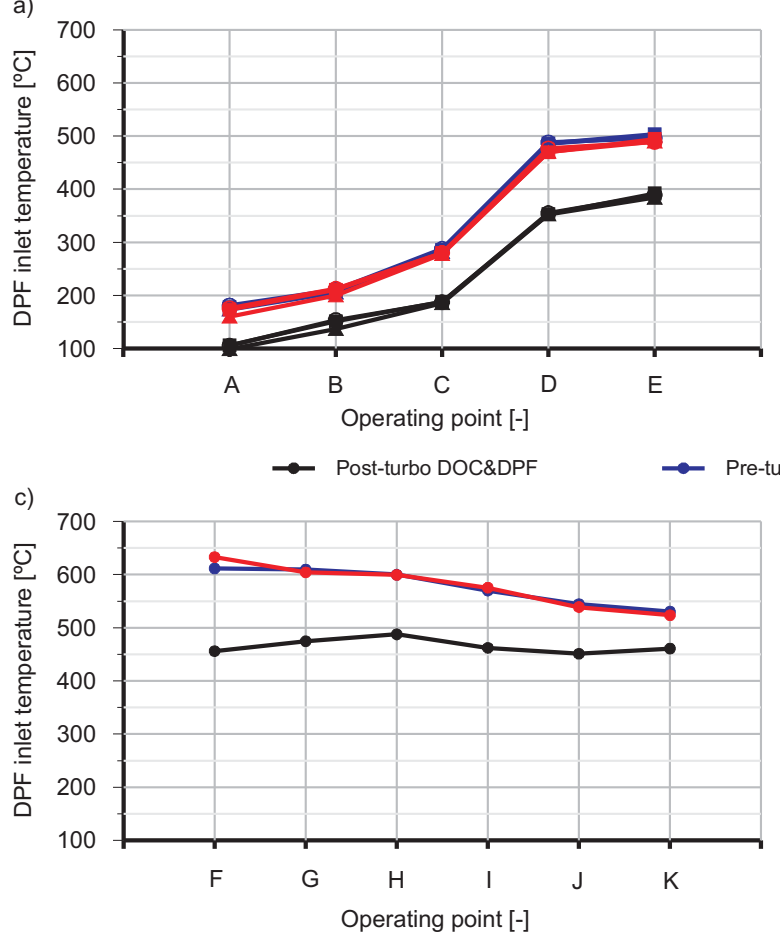

b)

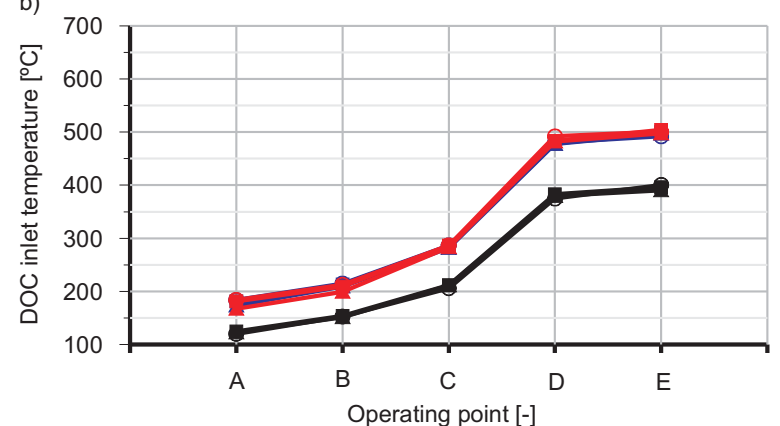

$\because$ Pre-turbo DOC\&DPF

d)

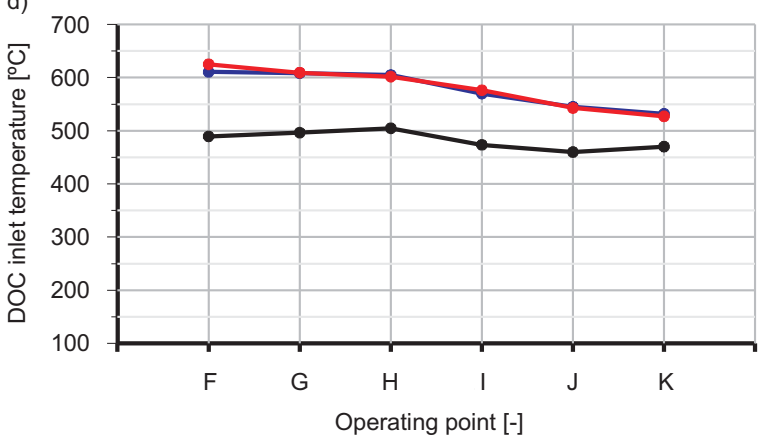

Operating point [-]

Figure 6: DPF and DOC inlet temperature as a function of the aftertreatment configuration and the steady-state operating point. 
a)
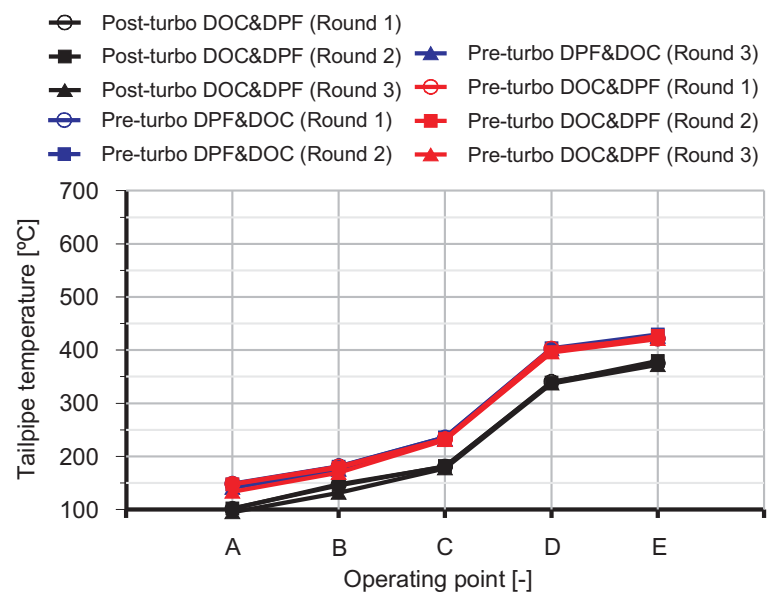

b) $\rightarrow$ Post-turbo DOC\&DPF $\multimap$ Pre-turbo DPF\&DOC $\rightarrow$ Pre-turbo DOC\&DPF

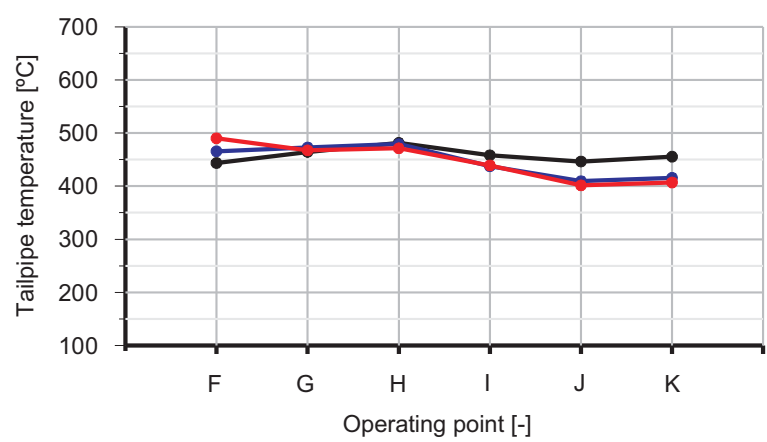

Figure 7: Tailpipe gas temperature as a function of the aftertreatment configuration and the steady-state operating point. 

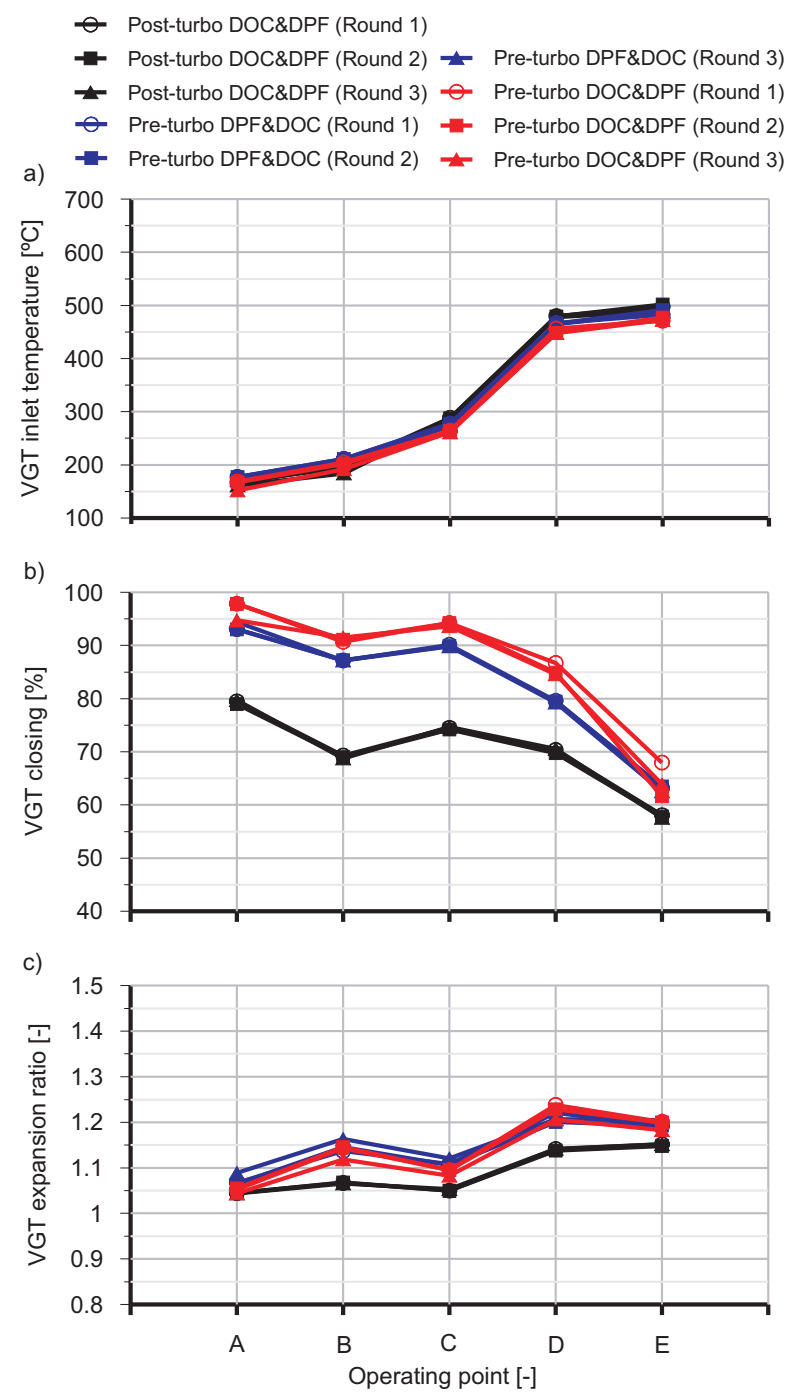

Figure 8: VGT operating conditions as a function of the aftertreatment configuration and the steady-state operating point at low engine load. 

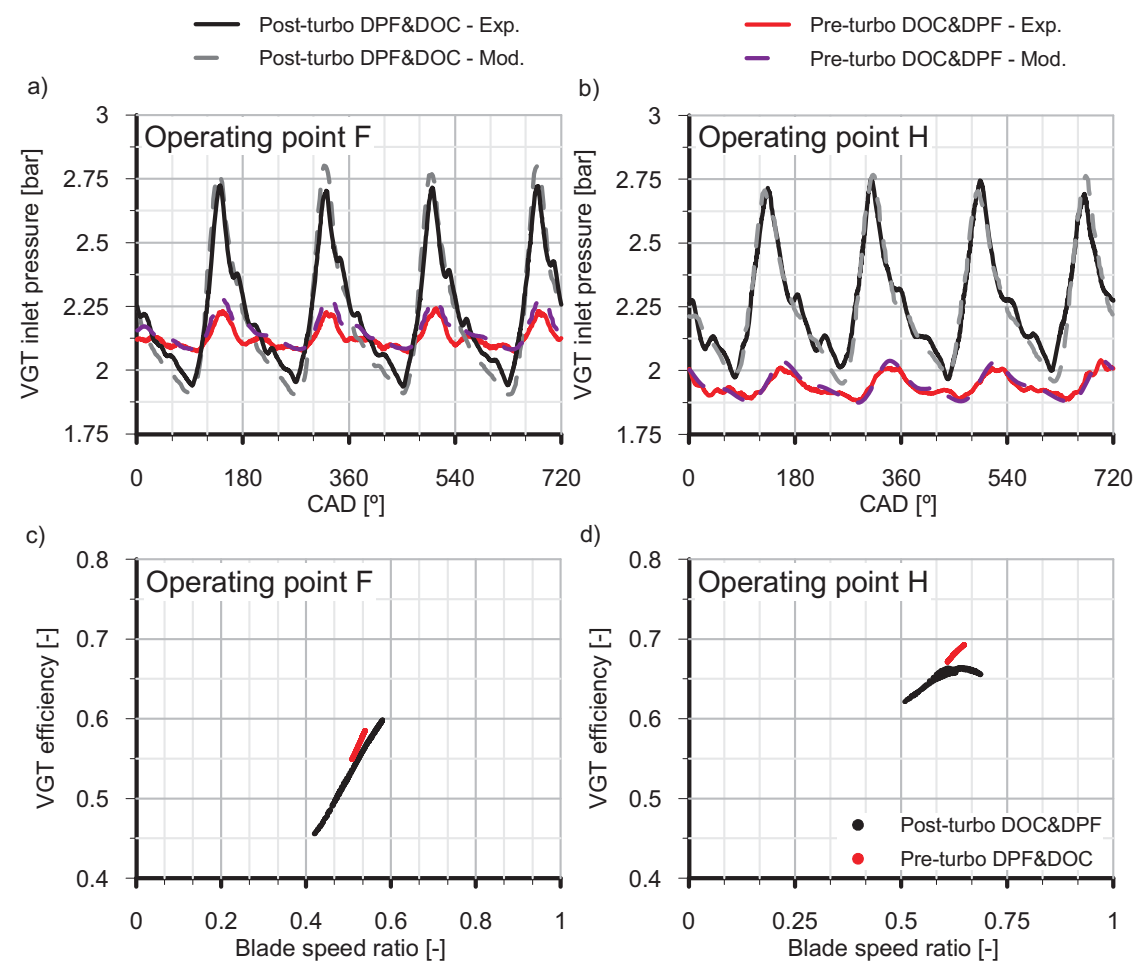

Figure 9: Modelled instantaneous VGT inlet pressure and VGT efficiency as a function of the aftertreatment configuration in operating points F and $\mathrm{H}$. 


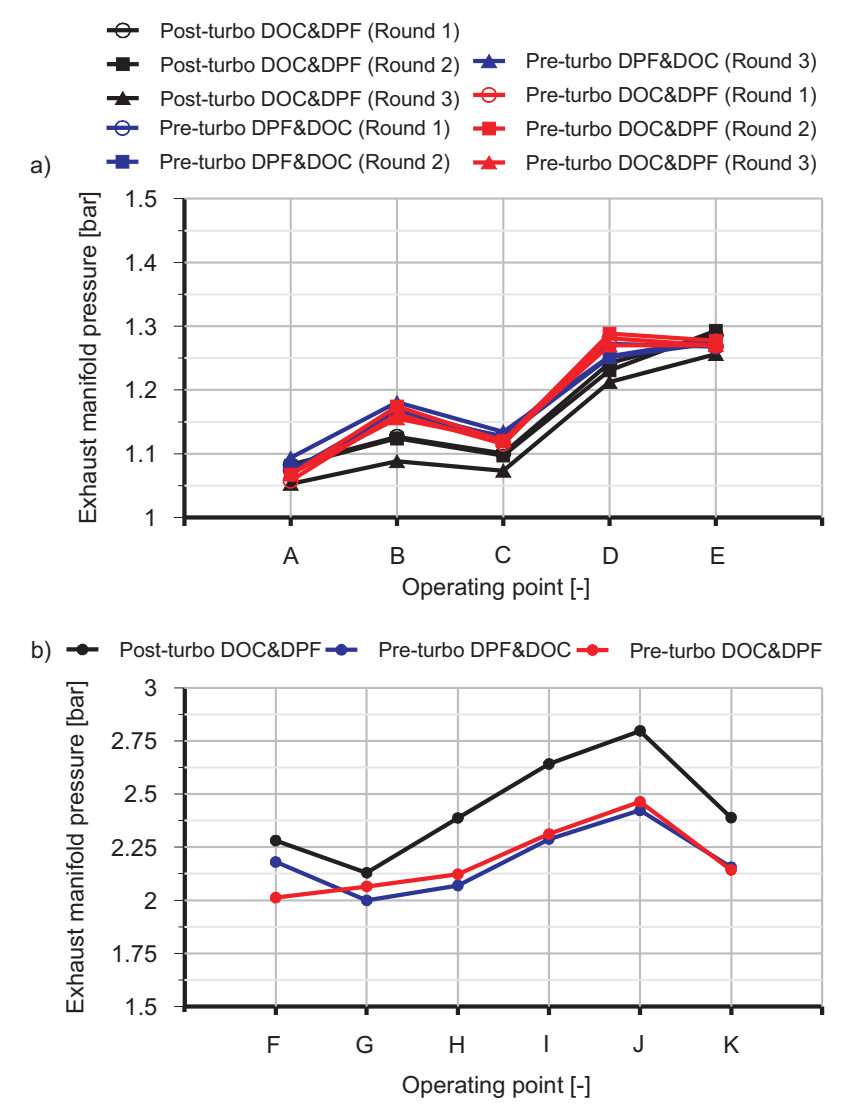

Figure 10: Exhaust manifold pressure as a function of the aftertreatment configuration and the steady-state operating point. 

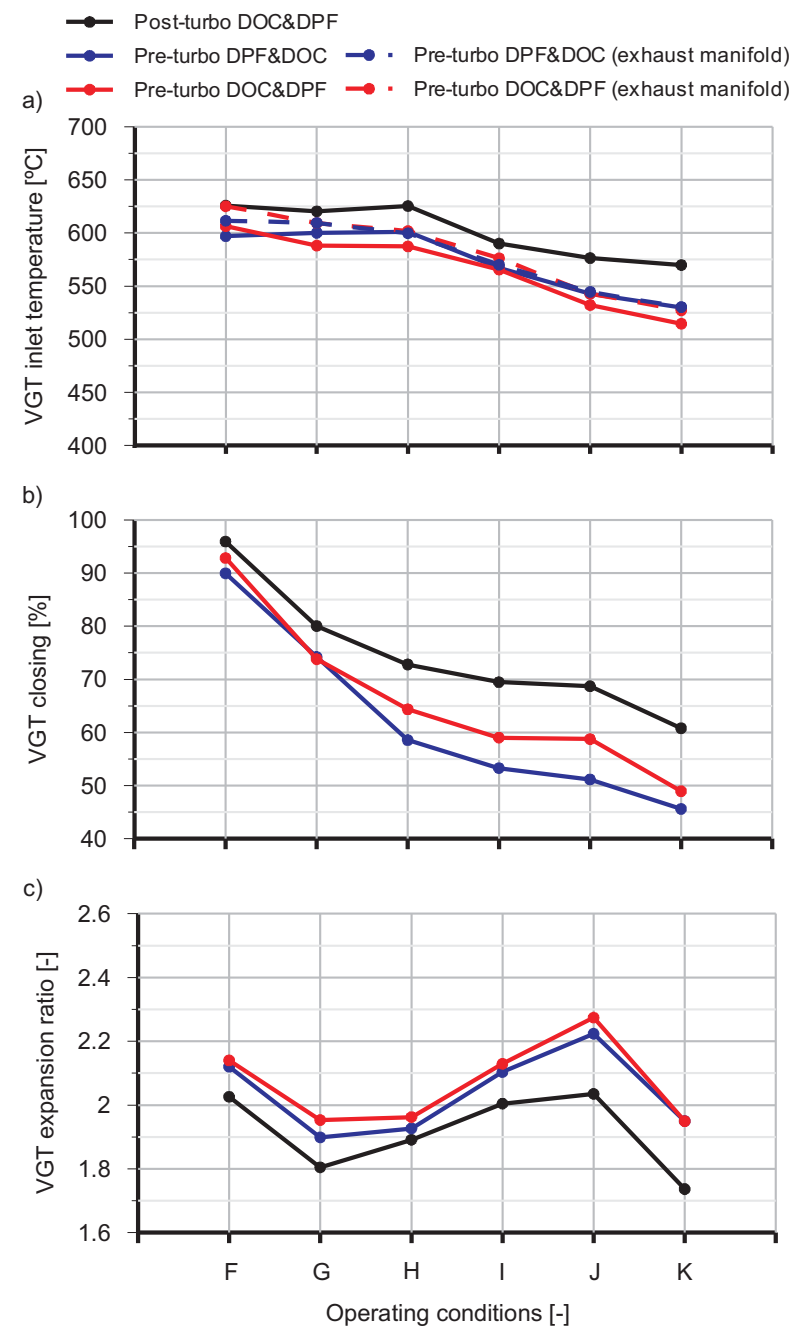

Figure 11: VGT operating conditions as a function of the aftertreatment configuration and the steady-state operating point at medium-high load. 

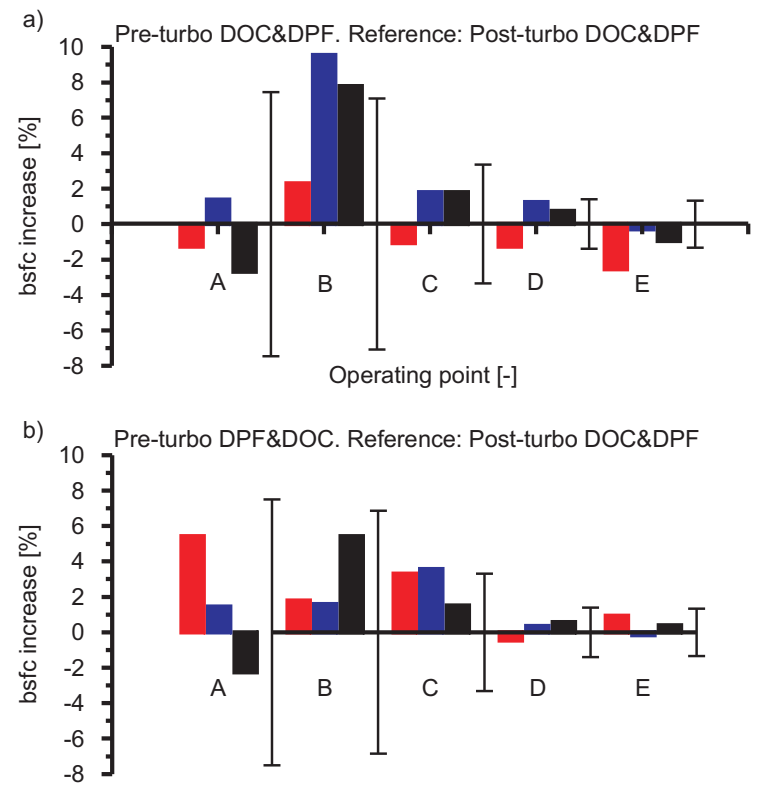

Figure 12: Variation in bsfc due to the pre-turbo aftertreatment placement: operating points of low load.

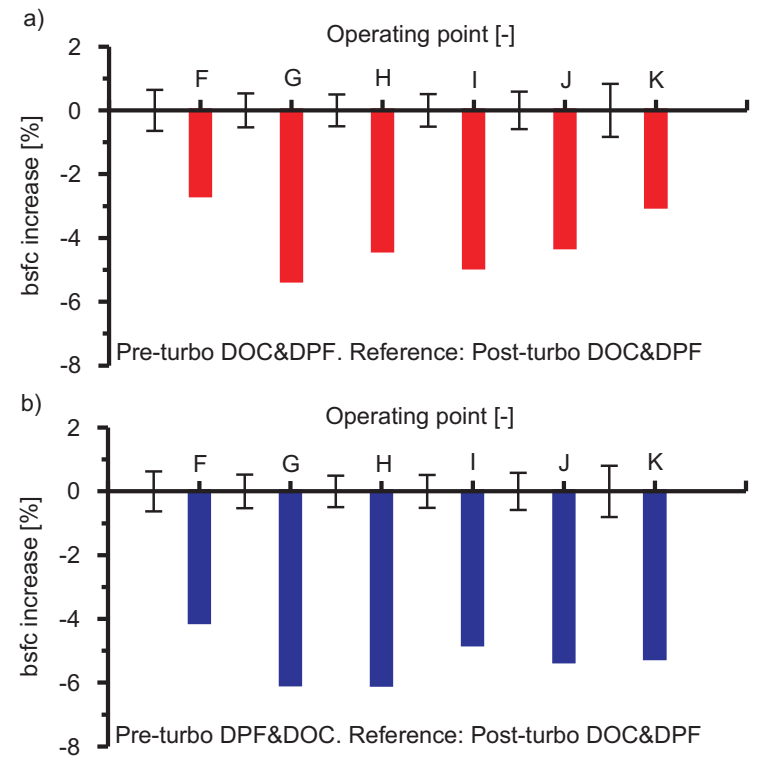

Figure 13: Variation in bsfc due to the pre-turbo aftertreatment placement: operating points of medium-high load. 
Collected soot mass during the round
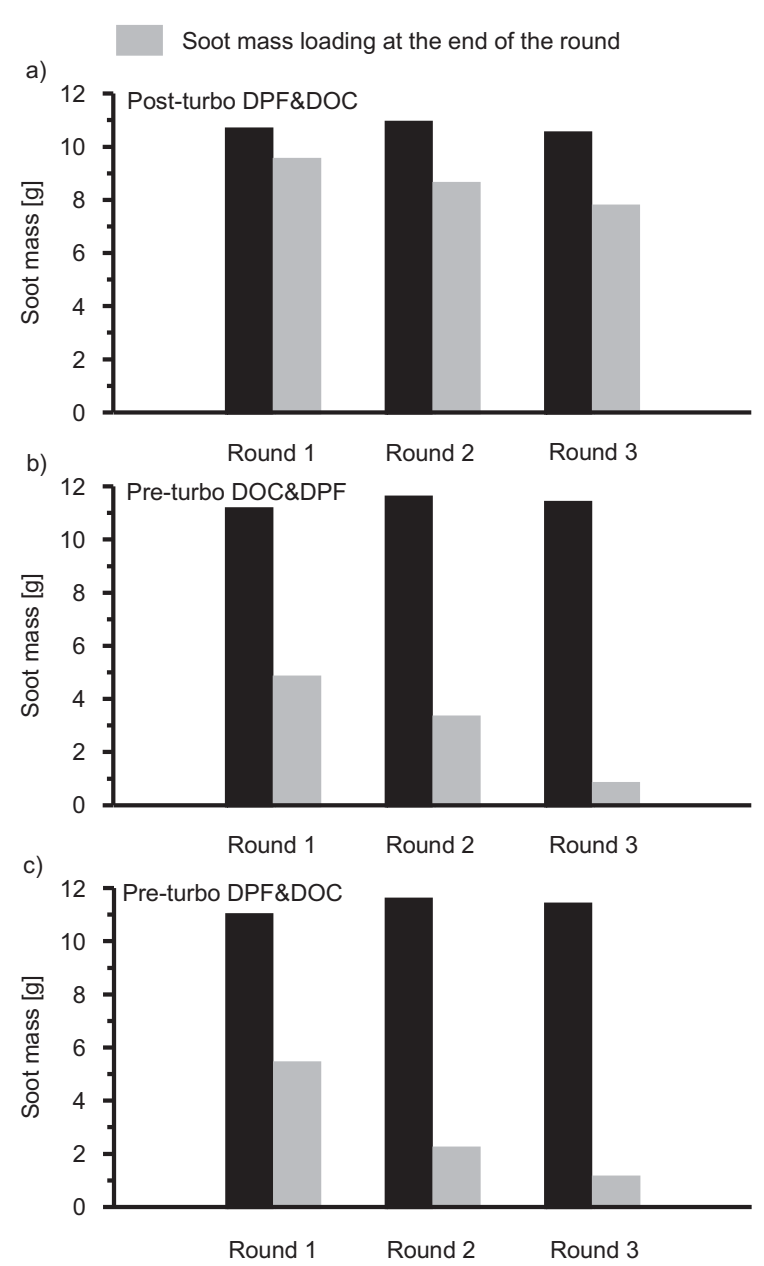

Figure 14: Collected soot mass against soot mass remaining in the DPF as a function of the aftertreatment placement and round. 
a)
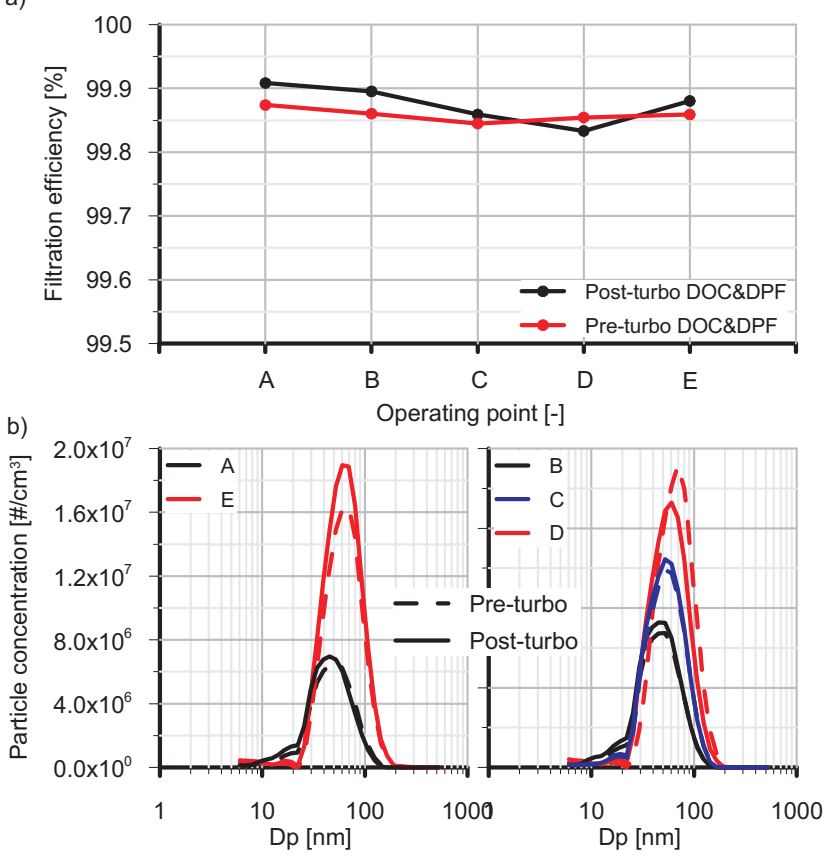

Figure 15: a) DPF filtration efficiency based on particle concentration; b) Raw particle concentration against particle size distribution as a function of the aftertreatment configuration and the steady-state operating points at low engine load. 
Post-turbo DOC\&DPF (Round 1)

$\rightarrow$ Post-turbo DOC\&DPF (Round 2) $₫$ Pre-turbo DPF\&DOC (Round 3)

— Post-turbo DOC\&DPF (Round 3) $\approx$ Pre-turbo DOC\&DPF (Round 1)

$\vartheta$ Pre-turbo DPF\&DOC (Round 1) $\Rightarrow$ Pre-turbo DOC\&DPF (Round 2)

a)
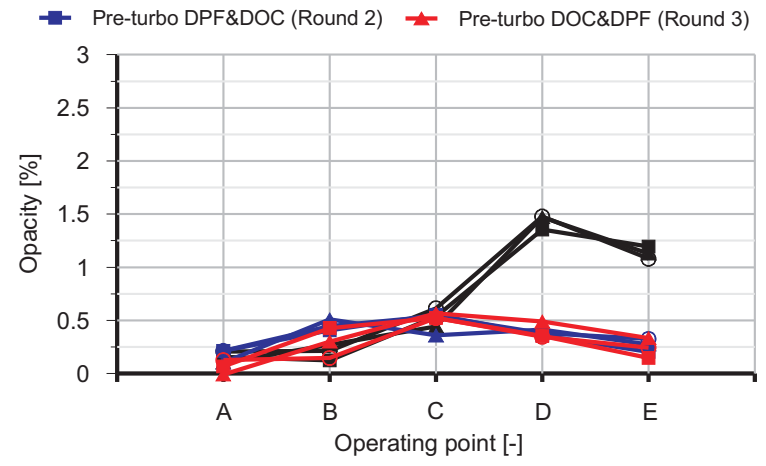

b) $\rightarrow$ Post-turbo DOC\&DPF $\rightarrow$ Pre-turbo DPF\&DOC $\leadsto$ Pre-turbo DOC\&DPF

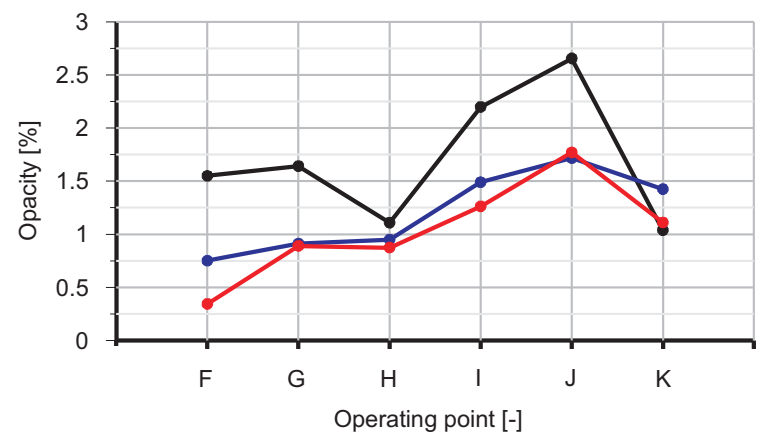

Figure 16: Tailpipe opacity as a function a of the aftertreatment configuration and the engine operating point. 

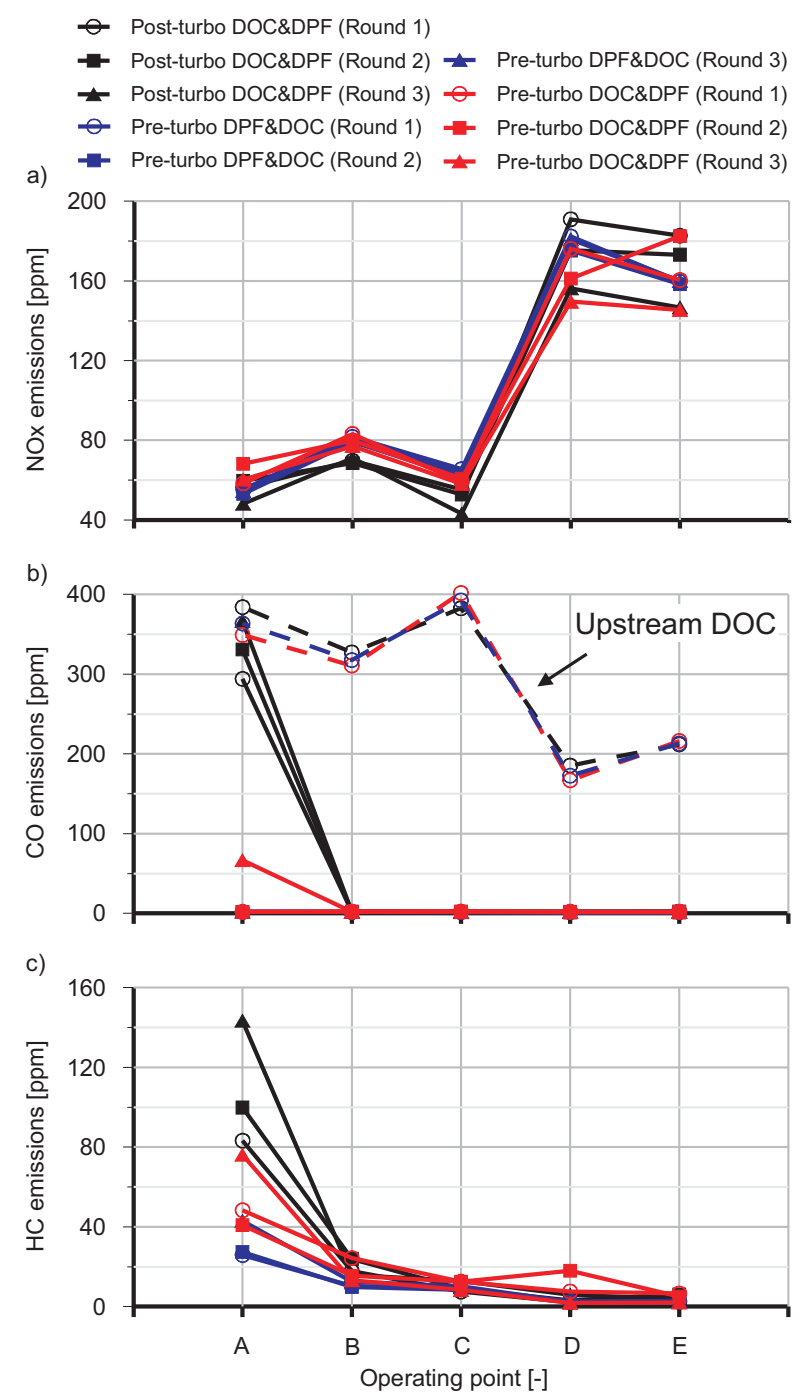

Figure 17: Regulated tailpipe gas emissions as a function a of the aftertreatment configuration and the engine operating point at low load. 


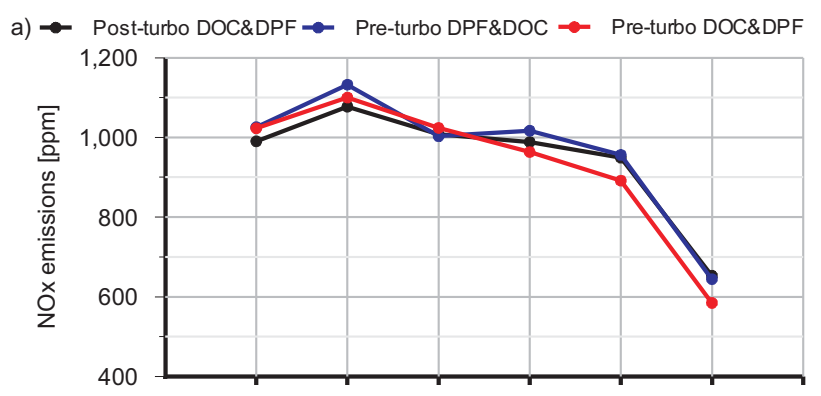

b)

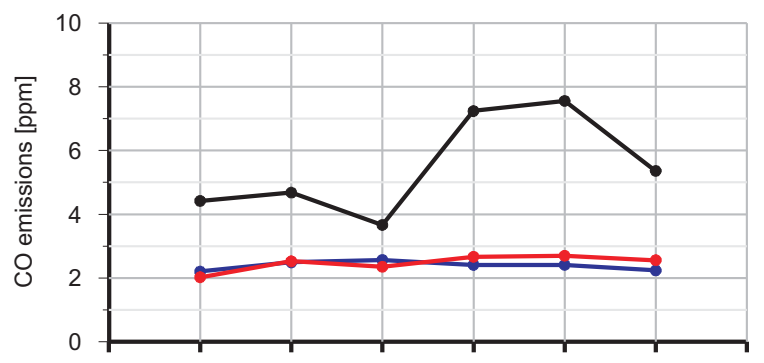

c)

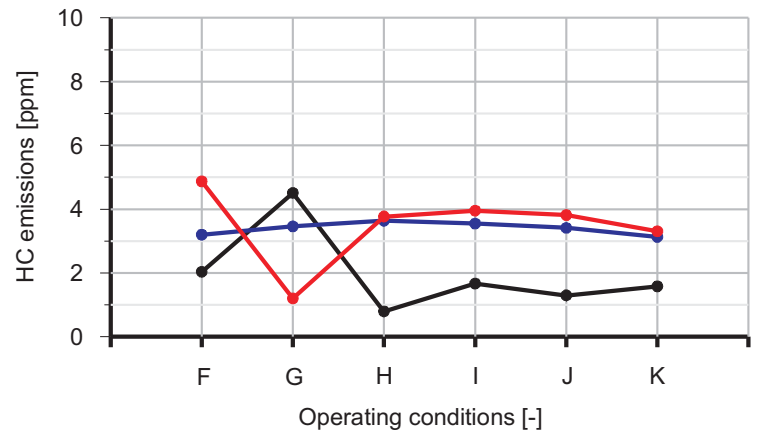

Figure 18: Regulated tailpipe gas emissions as a function of the aftertreatment configuration and the engine operating point at medium-high load. 